\title{
Valproic acid, an anti-epileptic drug and a histone deacetylase inhibitor, in combination with proteasome inhibitors exerts antiproliferative, pro-apoptotic and chemosensitizing effects in human colorectal cancer cells: Underlying molecular mechanisms
}

\author{
MOHAMED-SALAH I. ABAZA ${ }^{1}$, ABDUL-MAJEED BAHMAN ${ }^{1}$ and RAJA'A J. AL-ATTIYAH ${ }^{2}$ \\ ${ }^{1}$ Department of Biological Sciences, Faculty of Science, ${ }^{2}$ Department of Microbiology, \\ Faculty of Medicine, Kuwait University, Safat 13060, Kuwait
}

Received January 31, 2014; Accepted May 15, 2014

DOI: $10.3892 / \mathrm{ijmm} .2014 .1795$

\begin{abstract}
Although the therapeutic efficacy of valproic acid (VPA) has been observed in patients with solid tumors, the very high concentration required to induce antitumor activity limits its clinical utility. The present study focused on the development of combined molecular targeted therapies using VPA and proteasome inhibitors (PIs: MG132, PI-1 and PR-39) to determine whether this combination of treatments has synergistic anticancer and chemosensitizing effects against colorectal cancer. Furthermore, the potential molecular mechanisms of action of the VPA/PI combinations were evaluated. The effects of VPA in combination with PIs on the growth of colorectal cancer cells were assessed with regard to proliferation, cell cycle, apoptosis, reactive oxygen species (ROS) generation and the expression of genes that control the cell cycle, apoptosis and pro-survival/stress-related pathways. Treatment with combinations of VPA and PIs resulted in an additive/synergistic decrease in colorectal cancer cell proliferation compared to treatment with VPA or PIs alone. The combination treatment was associated with a synergistic increase in apoptosis and in the number of cells arrested in the $\mathrm{S}$ phase of the cell cycle. These events were associated with increased ROS generation, pro-apoptotic gene expression and stress-related gene expression. These events were also associated with the decreased expression of anti-apoptotic genes and pro-survival genes. The combination of VPA with MG132 or PI-1 enhanced the chemosensitivity of the SW1116 (29-185-fold) and SW837 (50-620-fold) colorectal
\end{abstract}

Correspondence to: Dr Mohamed-Salah Abaza, Department of Biological Sciences, Faculty of Science, Kuwait University, Safat 13060, Kuwait

E-mail: abazama@yahoo.com

Key words: valproic acid, proteasome inhibitors, antimitogenic effects, cell cycle, apoptosis, pro-survival and stress-related gene expression, chemosensitization cancer cells. By contrast, the combination of VPA/PR-39 induced a pronounced increase in the chemosensitivity of the SW837 (16-54-fold) colorectal cancer cells. These data provide a rational basis for the clinical use of this combination therapy for the treatment of colorectal cancer.

\section{Introduction}

Histone deacetylase (HDAC) activity has been shown to be upregulated in cancer cells. It is considered that this upregulation results in the repression of tumor suppressor gene products, such as p53, rendering HDACs an attractive drug target. In cell culture models, HDAC inhibitors (HDACIs) have been shown to decrease proliferation rates, induce apoptosis and induce autophagy-related cell death in several cancer cell lines. Due to their relative specificity toward cancer cells, HDACIs represent a new class of cancer treatment agents that are generally well tolerated (1).

Short-chain fatty acids, such as butyric and valproic acid (VPA) were the first HDACIs to be identified as tumor growth inhibitors and inducers of apoptosis both in vitro and in vivo. However, they were found to have low potency (2). Despite such weak in vitro activity, the anticancer effects of VPA have been investigated in preclinical models of skin, breast, colon, prostate and small cell lung cancer, and the drug is currently being used in phase I-III clinical trials (3). However, the therapeutic doses of VPA are very high and cause side-effects severe enough to limit its usage.

Despite their promising activity in preclinical models, HDACIs have demonstrated modest antitumor activity as single-agent therapy in solid malignancies (4). Thus, their use in combination treatments with other agents may be the key to optimizing their efficacy (4). HDACIs have shown synergistic or additive antitumor effects when combined with conventional anticancer drugs, targeted agents and radiation (4,5).

The rationale to targeting the proteasome in cancer arises from evidence that indicates that malignant cells accumulate misfolded/damaged proteins, which are disposed of by the proteasome, suggesting that tumor cells have a stronger dependency on proteasome activity compared to that of normal 
cells (6). The $26 \mathrm{~S}$ proteasome is the primary subcellular component of the protein degradation pathway that regulates the turnover of proteins involved in cell cycle progression and apoptosis, such as the p21 cyclin-dependent kinase (CDK) inhibitor $(\mathrm{CDKI})$, cyclins and $\mathrm{I} \kappa \mathrm{B}$, a regulator of nuclear factor- $\kappa \mathrm{B}(\mathrm{NF} \kappa \mathrm{B})$ transcriptional activity. Validation of the proteasome as a therapeutic target has come with the FDA approval of bortezomib, an inhibitor of the $20 \mathrm{~S}$ proteasome (7).

In vitro studies have demonstrated that the simultaneous targeting of HDACs and the $26 \mathrm{~S}$ proteasome produces a synergistic inhibition of cell proliferation and induction of apoptosis in pancreatic cancer cell lines (8), multiple myeloma (9), lung cancer and hepatoma cell lines (10). These effects are greater than those observed with treatment with either agent alone. In the present study, we examined the effects of combining HDAC inhibition via VPA with proteasome inhibition via MG132, PI-1 or PR-39 on colorectal cancer cell lines in vitro, with respect to their potential synergistic effects on cell proliferation. Our hypothesis was that these two agents act synergistically to inhibit cell growth and induce apoptosis, as well as potentiate the sensitivity of cancer cells to conventional chemotherapeutic drugs with different modes of action in human colorectal cancer cells. We also sought to investigate the molecular mechanisms of such a synergy by assessing the effects of the combination therapy on the cell cycle, apoptosis and downstream effector pathways. The aim of our study was to provide evidence to support a mechanism-based regimen in the treatment of colorectal cancer.

\section{Materials and methods}

Cells and cell culture. Human colorectal cancer cell lines (SW1116 and SW837) and normal human fibroblasts (CRL1554) were obtained from the American Type Culture Collection (ATCC; Manassas, VA, USA). The SW1116 and SW837 cells were cultured in 90\% Leibovitz's L15 medium supplemented with $10 \%$ heat-inactivated fetal bovine serum (FBS) and grown at $37^{\circ} \mathrm{C}$ in a non- $\mathrm{CO}_{2}$ incubator. The CRL1554 cells were cultured in Eagle's minimum essential medium (EMEM, 90\%) supplemented with $10 \%$ heat-inactivated FBS and grown at $37^{\circ} \mathrm{C}$ in the presence of $5 \% \mathrm{CO}_{2}$ and $95 \%$ ambient air.

Chemicals and reagents. VPA was purchased from Sigma-Aldrich (St. Louis, MO, USA). It was dissolved in sterile $\mathrm{ddH}_{2} \mathrm{O}$ to a final concentration of $100 \mathrm{mM}$ and stored at $-20^{\circ} \mathrm{C}$. This stock solution was diluted to the desired concentrations with L15 medium and used in the various assays. The proteasome inhibitors, MG132, proteasome inhibitor-1 (PI-1) and PR-39, were obtained from Biomol International (Plymouth Meeting, PA, USA). Trypsin, Leibovitz's L-15 medium and EMEM, FBS and penicillin/streptomycin solution (200X) were obtained from Mediatech, Inc. (Herndon, VA, USA). An Annexin V-FITC apoptosis detection kit was obtained from BD Hoffmann-Laroche Inc. (Nutley, NJ, USA). A DNA-prep kit was obtained from Beckman Coulter (Miami, FL, USA). All reagents for RT-PCR and real-time (quantitative) PCR (qPCR) were obtained from Applied Biosystems (Foster City, CA, USA). Nuclear/cytosol and mitochondria/ cytosol fractionation kits were obtained from BioVision, Inc. (Mountain View, CA, USA). A 20S Proteasome assay kit for
Drug Discovery was purchased from Biomol International. The cDNA reverse transcription kit, primers and target gene expression probes were obtained from Applied Biosystems. Antibodies against phospho-c-Jun N-terminal kinase (p-JNK), phospho-extracellular signal-regulated kinase 1/2 (p-ERK1/2) and phospho-Akt (p-Akt) were purchased from Cell Signaling Technology (Beverly, MA, USA). Anti-p65 and anti- $\beta$-actin antibodies were purchased from Santa Cruz Biotechnology, Inc. (Santa Cruz, CA, USA and Cambridge, UK). All other reagents were purchased from Sigma-Aldrich. Plasticware was purchased from Falcon Laboratories (Franklin Lakes, NJ, USA).

Cell proliferation assay. Cell proliferation assay was performed using a 3-(4,5-dimethylthiazol-2-yl)-2,5-diphenyltetrazolium bromide (MTT) assay, as previously described (11). The cells were treated with various concentrations of VPA (0.5-8 mM) for $24 \mathrm{~h}$ and then exposed to MG132 (0.15 and $0.25 \mu \mathrm{M}), \mathrm{PI}-1$ (7.8 and $15.6 \mathrm{nM}$ ) or PR-39 (106 and $112 \mathrm{pM}$ ) for an additional $48 \mathrm{~h}$. For single-agent treatment, the cells were exposed to VPA for $72 \mathrm{~h}$. Upon the completion of the treatments, the media were discarded and $100 \mu \mathrm{l} /$ well of MTT $(5 \mathrm{mg} / \mathrm{ml}$ in culture medium filter-sterilized) was added, and the plates were incubated for $4 \mathrm{~h}$ at $37^{\circ} \mathrm{C}$. The resulting formazan crystals were dissolved in $200 \mu \mathrm{l} /$ well of DMSO:ethanol $(1: 1 \mathrm{v} / \mathrm{v})$ for $20 \mathrm{~min}$ at ambient temperature and the absorbance was recorded at $\lambda 540$ and $650 \mathrm{~nm}$ using an ELISA plate reader. The control cells were incubated in medium supplemented with $0.2 \%$ DMSO alone. At this concentration, DMSO has no effect on the growth and survival of cells. The effects of the combined treatment with VPA $(1 \mathrm{mM}) / \mathrm{MG} 132(0.2 \mu \mathrm{M})$, VPA $(1 \mathrm{mM}) / \mathrm{PI}-1(10 \mathrm{nM})$ and VPA $(1 \mathrm{mM}) / \mathrm{PR}-39(212 \mathrm{pM})$ on the normal human fibroblasts, CRL1554, were also monitored by MTT assay and an inverted microscope.

Colony formation assay. A colony formation assay was carried out as previously described (11) to confirm the effects of VPA, PIs (MG132, PI-1 or PR-39) and their combinations on the colorectal cancer cells. Briefly, the SW1116 and SW837 cells $\left(2.5 \times 10^{5}\right.$ cells $\left./ \mathrm{ml}\right)$ were seeded into 24 -well plates and incubated for $18 \mathrm{~h}$. The cells were then treated with VPA (2.5 mM) or the PIs MG132 (1.5 $\mu \mathrm{M})$, PI-1 (36 nM), or PR-39 $(2 \mathrm{nM})$, as well as combinations of VPA with each of the PIs. After $24 \mathrm{~h}$, the cells were trypsinized, counted and plated at 500 cells $/ \mathrm{ml}$ into a 6 -well plate and incubated for 10-14 days. The cells were finally fixed in $100 \%$ methanol for $30 \mathrm{~min}$ at room temperature and stained with $0.1 \%$ crystal violet for $1 \mathrm{~h}$. The stained colonies were counted and compared with an untreated control sample.

Determination of HDAC activity. A colorimetric HDAC activity assay kit (BioVision, Inc.) was used to monitor HDAC activity in the cancer cell nuclear extracts, according to the manufacturer's instructions. The SW1116 and SW837 colorectal cancer cells $\left(2.5 \times 10^{5}\right.$ cells $\left./ \mathrm{ml}\right)$ were seeded into 24-well plates and incubated for $18 \mathrm{~h}$, followed by treatment with VPA $(2.5 \mathrm{mM})$ for an additional $24 \mathrm{~h}$. Nuclear extracts of the untreated and VPA-treated cells $(50 \mu \mathrm{g})$ were diluted with $\mathrm{ddH}_{2} \mathrm{O}$ to a final volume of $85 \mu \mathrm{l}$ in each well of a 96-well

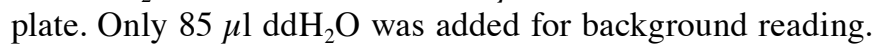


For a positive control, $10 \mu \mathrm{l}$ of HeLa nuclear extract were

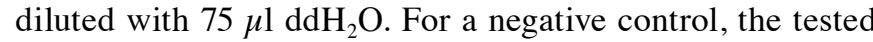
nuclear extract was diluted to $83 \mu \mathrm{l}$, and then $2 \mu \mathrm{l}$ of TSA (HDACI, $1 \mathrm{mM}$ ) were added. Alternatively, a known sample containing no HDAC activity was used as a negative control. Ten microliters of the 10X HDAC assay buffer and $5 \mu \mathrm{l}$ of the HDAC colorimetric substrate [Boc-Lys(Ac)-pNA, $10 \mathrm{mM}$ were added to each well and mixed thoroughly, and the plates were then incubated at $37^{\circ} \mathrm{C}$. After $1 \mathrm{~h}$, the reaction was terminated by the addition of $10 \mu \mathrm{l}$ of lysine developer, mixed well and then incubated at $37^{\circ} \mathrm{C}$ for a further $30 \mathrm{~min}$. Absorbance was recorded at 400 or $405 \mathrm{~nm}$ using an ELISA plate reader.

Determination of proteasome activity. Proteasome activity, in the cancer cell extracts, was monitored by using a $20 \mathrm{~S}$ proteasome assay kit for Drug Discovery (Biomol International) according to the manufacturer's instructions. Briefly, the SW1116 and SW837 cells $\left(2.5 \times 10^{5}\right.$ cells $\left./ \mathrm{ml}\right)$ were seeded into 24 -well plates and incubated for $18 \mathrm{~h}$, and then treated with the PIs, MG132 (1.5 $\mu \mathrm{M})$, PI-1 (36 nM), or PR-39 (2 nM) for $24 \mathrm{~h}$. A nuclear/ cytosolic fractionation kit (BioVision, Inc.) was used to prepare the cell extracts of the untreated and treated cells. Finally, the cytosolic extracts $(0.5 \mu \mathrm{g})$, positive (epoxomicin) and negative (no 20S proteosome) controls were incubated with $75 \mu \mathrm{M}$ proteasome substrate (Suc-LLVY-AMC) in $100 \mu$ l assay buffer (20 mM Tris- $\mathrm{HCl}, \mathrm{pH} 8.0$ ) for $90 \mathrm{~min}$ at $37^{\circ} \mathrm{C}$. Fluorescence from 7-amido-4-methyl-coumarin (AMC) was measured using a VersaFluor $^{\mathrm{TM}}$ fluorometer with excitation at $\lambda 360 \mathrm{~nm}$ and emission $\lambda 460$ nm (Bio-Rad Laboratories, Inc., Hercules, CA, USA).

Measurement of reactive oxygen species (ROS) production. The extent of ROS generation was analyzed by quantifying the fluorescence intensity of 2',7'-dichlorofluorescein diacetate (DCFH-DA) (Sigma-Aldrich), as previously described (12). DCFH-DA is a stable, non-fluorescent cell-permeable compound that fluoresces (dichlorofluorescein) in the presence of active radicals and emits green fluorescence upon excitation at $485 \mathrm{~nm}$. The SW1116 and SW837 cells $\left(2.5 \times 10^{5}\right.$ cells $\left./ \mathrm{ml}\right)$ were seeded into 24-well plates and incubated for $18 \mathrm{~h}$. The cells were then treated with VPA $(2.5 \mathrm{mM})$ or the PIs: MG132 (1.5 $\mu \mathrm{M})$, PI-1 (36 nM) or PR-39 (2 nM), or a combination of VPA with each of the PIs, or the solvent alone as described above. After $48 \mathrm{~h}$, the cells were washed and subsequently incubated with $10 \mu \mathrm{M}$ DCFH-DA in phosphate-buffered saline (PBS) for $30 \mathrm{~min}$ at $37^{\circ} \mathrm{C}$. Fluorescence was analyzed on a microtiter plate reader using excitation at $485 \mathrm{~nm}$ and emission at $535 \mathrm{~nm}$. The production of ROS was determined by comparing the intensity of fluorescence in the treated vs. untreated cells. The free radical scavenger, $\mathrm{L}-\mathrm{N}$-acetylcysteine (L-NAC) (Sigma-Aldrich), was used to assess the functional role of ROS generation in cell death. The cells were pre-incubated with $15 \mathrm{mM} \mathrm{L-NAC}$ for $3 \mathrm{~h}$, followed by treatment with VPA, PIs, or combinations of both for $48 \mathrm{~h}$. The assessment of cell death was carried out as described above.

Cell cycle analysis. Flow cytometry was used to determine the distribution of cells in the various cell cycle phases $\left(\mathrm{G}_{0} /\right.$ $\mathrm{G}_{1}, \mathrm{~S}$ and $\mathrm{G}_{2} / \mathrm{M}$ ) by measuring the DNA content of the nuclei labeled with propidium iodide as previously described (12). Briefly, the SW837 cells $\left(2.5 \times 10^{5}\right.$ cells $\left./ \mathrm{ml}\right)$ were seeded into 24-well plates and incubated for $18 \mathrm{~h}$. The cells were then treated with either VPA $(2.5 \mathrm{mM})$, PIs MG132 $(1.5 \mu \mathrm{M})$, PI-1 (36 nM) or PR-39 (2 nM), or a combination of VPA and a PI for $24 \mathrm{~h}$. The untreated and drug-treated cancer cells were collected by trypsinization, washed with cold PBS and counted. The cells were then processed by using a DNA-prep kit (Beckman Coulter) and a DNA-Prep EPICS workstation (Beckman Coulter) as follows: the cells were treated with a cell-membrane permeabilizing agent followed by propidium iodide and RNase. The samples were then incubated at room temperature for $15 \mathrm{~min}$ before being analyzed using a FC500 flow cytometer (Beckman Coulter, Nyon, Switzerland). The Phoenix statistical software package with advanced DNA cell cycle software (Phoenix Flow Systems, San Diego, CA, USA) was used to calculate the percentage of cells in the various cell cycle phases.

Assessment of apoptosis. An Annexin V-FITC apoptosis detection kit (BD Hoffmann-La Roche Inc.) was used to determine the level of apoptotic cell death in the colorectal cancer cells treated with VPA, PIs, or a combination of both according to the manufacturer's instructions. Briefly, the SW837 cells $\left(2.5 \times 10^{5}\right.$ cells $\left./ \mathrm{ml}\right)$ were seeded into 24 -well plates and incubated for $18 \mathrm{~h}$. The cells were then treated with VPA (2.5 mM), the PIs, MG132 (1.5 $\mu \mathrm{M})$, PI-1 (36 nM) or PR-39 $(2 \mathrm{nM})$, and a combination of VPA and one of the inhibitors for $24 \mathrm{~h}$. The control and treated cells were resuspended in $100 \mu \mathrm{l}$ of staining solution containing Annexin V fluorescein and propidium iodide in HEPES buffer, incubated at room temperature for $15 \mathrm{~min}$, and finally analyzed by flow cytometry. Annexin V binds to cells that express phosphatidylserine on the outer layer of the cell membrane, while propidium iodide stains the cellular DNA of cells with a compromised cell membrane. This allows live cells (unstained with either of the fluorochromes) to be discriminated from apoptotic cells (stained only with Annexin V) and necrotic cells (stained with both Annexin $\mathrm{V}$ and propidium iodide).

Western blot analysis. The colorectal cancer cells, SW1116 and SW837 $\left(2.5 \times 10^{5}\right.$ cells $\left./ \mathrm{ml}\right)$, were seeded into 24 -well plates and allowed to grow for $18 \mathrm{~h}$. The cells were then treated with VPA $(2.5 \mathrm{mM})$, PI-1 (36 $\mathrm{nM})$ or a combination of both for $24 \mathrm{~h}$. Following treatment, the cells were rinsed with ice-cold PBS and cytosol, and then nuclear and mitochondrial fractions were prepared using cytosol/nuclear and cytosol/mitochondria fractionation kits (BioVision, Inc.) according to the manufacturer's instructions. Protein concentration was determined by the Bradford (13) method using bovine serum albumin (BSA) as a standard. Western blot analysis was carried out as previously described (14). Briefly, the cell lysates (50 $\mu \mathrm{g})$ were resolved by SDS-PAGE on 7.5-15\% slab gels, and proteins were transferred onto polyvinylidene difluoride membranes blocked in a PBS solution containing $0.1 \%$ Tween-20 and $5 \%(\mathrm{w} / \mathrm{v})$ dry skim milk for $30 \mathrm{~min}$ and incubated at $4^{\circ} \mathrm{C}$ overnight with primary antibodies against Bax, cytochrome $c$, $\mathrm{NF}-\kappa \mathrm{B}(\mathrm{p} 65), \mathrm{pAkt}, \mathrm{pJNK}, \mathrm{pERK} 1 / 2$ and $\beta$-actin. After washing with PBS containing 0.1\% Tween-20, the blots were incubated with an alkaline phosphatase-conjugated species specific $\operatorname{IgG}$ secondary antibody for $2 \mathrm{~h}$ at room temperature. Bound antibodies were detected using nitroblue tetrazolium 
and 5-bromo-4-chloro-3-indolyl phosphate. The specificities of the antibodies used in this study were examined by testing their reactivity with unrelated antigens, such as BSA. The signal intensities of the respective bands were quantified using a GS-800 calibrated imaging densitometer (Bio-Rad Laboratories, Inc.).

Analysis of mRNA expression of genes involved in the regulation of apoptosis and the cell cycle. The expression of genes involved in the regulation of the cell cycle and apoptosis was determined in the cells from the control and treated groups by reverse transcription-PCR and real-time PCR (qPCR) using an ABI 7000 SDS system (Applied Biosystems) and the comparative $\Delta \Delta \mathrm{Ct}$ method, as previously described (11). Ready-made assays-on-demand that target gene expression probes and primers were obtained from Applied Biosystems. The targets and Applied Biosystems assay numbers for the cell cycle-related genes were as follows: CDK1 (Hs00364293_m1), CDK4 (Hs00364847_m1), CDC25A (Hs00153168_m1), p15 (Hs00394703_m1), p19 (Hs00176481_m1), p21 (Hs00355782_m1) and p27 (Hs00197366_m1).

The targets and Applied Biosystems assay numbers for the pro-apoptotic and anti-apoptotic genes and caspases that were used in this study are as follows: Bax (Hs00180269_m1), Bad (Hs00188930_m1), Bim (Hs00375807_m1), apoptotic protease activating factor 1 (Apaf1; Hs00559441_m1), Bcl-2 (Hs00608023_m1), the X-linked inhibitor of apoptosis (XIAP; Hs00236913_m1), caspase-3 (Hs00234387_m1), caspase-8 (Hs01018151_m1), caspase-9 (Hs00154260_m1), the apoptosis-inducing factor (AIF; Hs00269879_ml) and FLIP (Hs00354474_ml). GAPDH was used as an endogenous control to normalize the expression values for each sample. For the comparative $\mathrm{Ct}$ method, we performed a two-step RT-PCR process using cDNA and carried out qPCR using the target gene expression assays and TaqMan Universal master mix (Applied Biosystems). The SW837 colorectal cancer cells were plated $\left(2.5 \times 10^{5}\right.$ cells $\left./ \mathrm{ml}\right)$ into 24 -well plates and incubated in a non- $\mathrm{CO}_{2}$ incubator for $18 \mathrm{~h}$. The cells were then treated with either VPA $(2.5 \mathrm{mM})$, the PIs MG132 $(1.5 \mu \mathrm{M})$, PI-1 (36 $\mathrm{nM})$ or PR-39 (2 nM), or a combination of VPA with each PI for $24 \mathrm{~h}$. mRNA was extracted using a nucleospin RNAII ready-to-use system (MACHEREY-NAGEL GmbH \& Co., Düren, Germany), and $200 \mathrm{ng} / \mu \mathrm{l}$ of mRNA was used in each RT reaction. First, DNA was eliminated by DNase-I treatment for $20 \mathrm{~min}$ at $25^{\circ} \mathrm{C}$, followed by heat inactivation for $10 \mathrm{~min}$ at $65^{\circ} \mathrm{C}$. cDNA synthesis was performed using a high capacity cDNA Reverse Transcription kit (Applied Biosystems) according to the manufacturer's instructions. For each sample, $2.5 \mu \mathrm{l}$ of cDNA and 12.5 $\mu \mathrm{l}$ of TaqMan Universal Master Mix (2X) were used, and the final volume was adjusted to $25 \mu 1$ with nuclease-free water in an optical 96-well reaction plate (Applied Biosystems). qPCR was performed on an ABI 7000 SDS system using ABI Prism SDS collection software version 1.1 (Applied Biosystems). The conditions for qPCR followed the instructions provided with the TaqMan Universal Master Mix: step $1,95^{\circ} \mathrm{C}$ for $10 \mathrm{~min}$; step 2, $94^{\circ} \mathrm{C}$ for $15 \mathrm{sec}$; and step $3,60^{\circ} \mathrm{C}$ for $1 \mathrm{~min}$. The samples were analyzed using ABI Prism SDS collection software version 1.1 by setting the base line between 3 and 15 and the threshold at 0.2 . The amount of target normalized to an endogenous reference and relative to a calibrator (untreated) was given by $2^{-\Delta \Delta C t}$ and the log comparative $\mathrm{Ct}$ was presented graphically.

Analysis of the chemosensitizing activity of VPA and PIs. The potential of the combined treatment with VPA and PIs (MG132, PI-1 or PR-39) to sensitize human colorectal cancer cells to standard chemotherapeutic drugs was investigated as previously described (12), with some modifications. Briefly, the SW1116 and SW837 colorectal cells $\left(27 \times 10^{3}\right.$ cells/well) were seeded into 96 -well plates and incubated for $18 \mathrm{~h}$. The cells were then treated for $24 \mathrm{~h}$ with various concentrations of

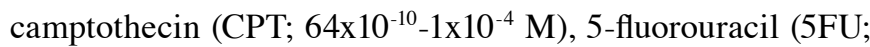
$\left.41.6 \times 10^{-9}-0.65 \times 10^{-3} \mathrm{M}\right)$, oxaliplatin (OXP; $\left.4 \times 10^{-10}-0.06 \times 10^{-4} \mathrm{M}\right)$,

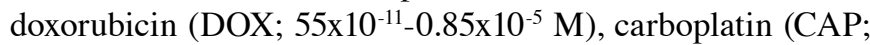
$\left.43.5 \times 10^{-10}-0.86 \times 10^{-4} \mathrm{M}\right)$, cisplatin (CIP; $\left.26.88 \times 10^{-9}-0.42 \times 10^{-3} \mathrm{M}\right)$, taxol (TAX; $93.44 \times 10^{-10}-1.4 \times 10^{-4} \mathrm{M}$ ), cyclophosphamide (CPA; $14 \times 10^{-9}-0.22 \times 10^{-3} \mathrm{M}$ ), vincristine (VCR; $16 \times 10^{-11}-2.5 \times 10^{-5} \mathrm{M}$ ), etoposide (ETP; $25.6 \times 10^{-10}-0.4 \times 10^{-4} \mathrm{M}$ ), ellipticine (ELP; $\left.12.8 \times 10^{-10}-0.2 \times 10^{-4} \mathrm{M}\right)$, amsacrine (AMS; $80 \times 10^{-11}-1.25 \times 10^{-5} \mathrm{M}$ ), homoharringtonine (HHG; $12.8 \times 10^{-11}-0.2 \times 10^{-5} \mathrm{M}$ ) and aphidicolin (APD; $17.28 \times 10^{-11}-0.27 \times 10^{-5} \mathrm{M}$ ). The drugs were then removed from the samples. At the end of treatment, the cells were washed with Hank's balanced salt solution (HBSS) and incubated with a combination of VPA $(1 \mathrm{mM}) / \mathrm{MG} 132$ $(0.25 \mu \mathrm{M})$, VPA $(1 \mathrm{mM}) / \mathrm{PI}-1(10 \mathrm{nM})$ and VPA $(1 \mathrm{mM}) / \mathrm{PR}-39$ (212 $\mathrm{nM}$ ) for $72 \mathrm{~h}$. An MTT assay was used to monitor the growth of the treated cells.

Statistical analyses. The results are expressed as the means \pm standard error of the mean (SEM) of at least 3 independent experiments. Statistical analyses were performed using SPSS-21 software. The statistical significance of the differences between the control and treated groups was determined by one-way ANOVA. P-values $<0.05$ were considered to indicate statistically significant differences.

\section{Results}

PIs potentiate the antimitogenic effect of VPA against human colorectal cancer cells. To determine whether the PIs (MG132, PI-1 and PR-39) enhance the cytotoxicity of VPA toward colorectal cancer cells, the cancer cells were treated with various concentrations of VPA (0.5-8.0 mM) alone, as well as in the presence of the tested PIs: MG132 (0.15 and $0.25 \mu \mathrm{M}$ ), PI-1 (7.8 and $15.6 \mathrm{nM}$ ) and PR-39 (106 and $212 \mathrm{pM})$. The concentrations used in this experiment were determined by an independent dose response experiment (data not shown).

When treated with various concentrations of VPA, the SW1116 and SW837 colorectal cancer cells displayed a doseand time-dependent growth inhibition. The $\mathrm{IC}_{50}$ values for the SW1116 and SW837 cells were 2.75 and $7.5 \mathrm{mM}$, respectively, indicating that the SW1116 cells are more sensitive than the SW837 cells, which demonstrated a resistance to VPA treatment. The combined treatment of VPA (0.5-8 mM) and MG132 $(0.15 \mu \mathrm{M})$ exerted a greater growth inhibitory effect for both the SW1116 ( IC $_{50} 2.25 \mathrm{mM}, \mathrm{P} \leq 0.803$ ) (Fig. 1A-a) and SW837 cells $\left(\mathrm{IC}_{50} 4.75 \mathrm{mM}, \mathrm{P} \leq 0.036\right.$ ) (Fig. 1A-d), compared to the resistance produced by single treatment with VPA. MG132 $(0.15 \mu \mathrm{M})$ slightly improved the sensitivity of the SW1116 [sensitization 
ratio (SR) 1.22] and SW837 (SR 1.60) cells to VPA. By contrast, the combined treatment with VPA and MG132 $(0.25 \mu \mathrm{M})$ led to a significantly greater growth inhibitory effect on the SW1116 cells $\left(\mathrm{IC}_{80} 1.0 \mathrm{mM}, \mathrm{P} \leq 0.002\right)$ compared to treatment with VPA alone $\left(\mathrm{IC}_{80} 6.75 \mathrm{mM}\right.$ for SW1116 cells; Fig. 1A-a). The addition of MG132 $(0.25 \mu \mathrm{M})$ markedly increased the sensitivity of the SW1116 cells (SR 6.75) to VPA. The combined treatment with VPA and MG132 $(0.25 \mu \mathrm{M})$ led to a greater growth inhibitory effect on the SW837 cells $\left(\mathrm{IC}_{80} 3.0 \mathrm{mM}\right)$ compared to treatment with VPA alone ( $\mathrm{IC}_{50} 7.5 \mathrm{mM}$; Fig. 1A-d).

Combined treatment with VPA (0.5-8.0 mM) and PI-1 $(7.8 \mathrm{nM})$ exerted a greater, although not significant, growth inhibitory effect on both the SW1116 ( $\left.\mathrm{IC}_{50} 2.0 \mathrm{mM}, \mathrm{P} \leq 0.607\right)$ (Fig. 1A-b) and SW837 cells $\left(\mathrm{IC}_{50} 5.25 \mathrm{mM}, \mathrm{P} \leq 0.154\right)$ (Fig. 1A-e) compared to that produced by treatment with VPA alone $\left(\mathrm{IC}_{50} 3.0 \mathrm{mM}\right.$ for the SW1116 celks and $\mathrm{IC}_{50} 6.75 \mathrm{mM}$ for the SW837 cells) (Fig. 1A-b and e). PI-1 (7.8 nM) moderately increased the sensitivity of both the SW1116 (SR 1.5) and SW837 cells (SR 1.30) to VPA. However, the combined treatment with VPA and PI-1 (15.6 nM) led to a much greater, statistically significant growth inhibitory effect on the SW1116 ( $\mathrm{IC}_{70} 1.75 \mathrm{mM}, \mathrm{P} \leq 0.013$; Fig. 1A-b) and SW837 cells $\left(\mathrm{IC}_{50} 3.25 \mathrm{mM}, \mathrm{P} \leq 0.002\right.$; Fig. 1A-e) compared to treatment with VPA alone. PI-1 (15.6 nM) markedly increased the sensitivity of both the SW1116 (SR 3.3) and SW837 cells (SR 2.1) to VPA.

Combined treatment with VPA $(0.5-8.0 \mathrm{mM})$ and PR-39 $(106 \mathrm{pM})$ exerted a slightly greater growth inhibitory effect on the SW1116 $\left(\mathrm{IC}_{50} 2.25 \mathrm{mM}, \mathrm{P} \leq 0.759\right)$ and $\mathrm{SW} 837$ cells $\left(\mathrm{IC}_{50} 6.75 \mathrm{mM}, \mathrm{P} \leq 0.388\right)$ than that produced by single treatment with VPA ( $\mathrm{IC}_{50}$ values equal to $3.0 \mathrm{mM}$ for SW1116 cells and $7.75 \mathrm{mM}$ for SW837 cells; Fig. 1A-c and f). PR-39 slightly improved the sensitivity of the SW1116 (SR 1.33) and SW837 cells (SR 1.15) to VPA. Combined treatment with VPA and PR-39 $(212 \mathrm{pM})$ exerted a significantly greater growth inhibitory effect on the SW1116 cells $\left(\mathrm{IC}_{50} 1.25 \mathrm{mM}, \mathrm{P} \leq 0.013\right.$; Fig. 1A-c), and an even more significant growth inhibitory effect on the SW837 cells ( $\mathrm{IC}_{50} 5.5 \mathrm{mM}, \mathrm{P} \leq 0.0001$; Fig. 1A-f) compared to the results obtained with treatment with VPA alone. Finally, PR-39 (212 pM) increased the sensitivity of both the SW1116 (SR 2.4) and SW837 cells (SR 1.41) to VPA.

The results of the growth inhibitory effects were confirmed by a colony formation assay. Treatment of the SW1116 cells with a combination of VPA and MG132 significantly inhibited colony formation (mean number of colonies, $82, \mathrm{P} \leq 0.0001$ ) compared to the untreated SW1116 cells (mean number of colonies, 245). Colony formation by the SW1116 cells was also significantly inhibited by the combined treatment with VPA and MG132 ( $\mathrm{P} \leq 0.0001)$ compared to treatment with either VPA (mean number of colonies, 169) or MG132 (mean number of colonies, 108) alone (Fig. 1B-a).

Treatment of the SW1116 cells with a combination of VPA and PI-1 significantly inhibited colony formation (mean number of colonies, 121, P $\leq 0.0001$ ) compared to the untreated SW1116 cells (mean number of colonies, 245). The same treatment also significantly inhibited the colony formation of the SW1116 cells $(\mathrm{P} \leq 0.001)$ compared to treatment with VPA alone (mean number of colonies, 169). This combined treatment decreased the number of colonies formed compared to the cells treated with PI-1 alone (mean number of colonies, 130). However, the difference in the number of colony formations was statistically insignificant $(\mathrm{P} \leq 0.407)$ (Fig. 1B-b).

Combined treatment with VPA and PR-39 significantly inhibited the colony formation of the SW1116 cells (mean number of colonies, $98, \mathrm{P} \leq 0.0001)$ compared to the untreated SW1116 cells (mean number of colonies, 245). The combined treatment also significantly inhibited the colony formation of the SW1116 cells compared to treatment with either VPA alone (mean number of colonies, 169, $\mathrm{P} \leq 0.0001$ ) or PR-39 alone (mean number of colonies, 126, $\mathrm{P} \leq 0.003$ ) (Fig. 1B-c).

The morphological changes of the human colorectal cancer cells following treatment with VPA, PIs, or a combination of both (Fig. 1C-a-f) clearly demonstrated the cytolytic effects of these treatments, and confirmed the results of the experiments analyzing the inhibitory effects.

Inhibition of HDAC and 26S proteasome activities and induction of ROS generation in cancer cells. To determine whether the antimitogenic activity of VPA is associated with the inhibition of intra-nuclear HDAC activity, HDAC activity was measured in nuclear fractions of untreated and VPA-treated SW837 colorectal cancer cells. The cancer cells treated with VPA showed a significant inhibition of HDAC activity $(\mathrm{P} \leq 0.0001)$ compared to the untreated cancer cells (Fig. 2A).

To determine whether the antimitogenic activities of the PIs included in this study are linked to the inhibition of intracellular proteasome activity, 26S proteasome activity was measured in both the untreated and PI-treated cancer cell extracts. The PI, PR-39, exerted a significant inhibitory effect on 26S proteasome activity $(\mathrm{P} \leq 0.0001)$ in the colorectal cancer cells compared to the untreated cancer cells (Fig. 2B). A significant inhibition of $26 \mathrm{~S}$ proteasome activity was also observed following treatment with the PIs, MG132 ( $\mathrm{P} \leq 0.001)$ and PI-1 ( $\mathrm{P} \leq 0.001)$, (data not shown).

ROS have been implicated in HDAC and PI-induced cytotoxicity in a number of different types of malignancies (15). Thus, the effects of VPA, PIs, or a combination of VPA and PIs on ROS generation in the human SW837 colorectal cancer cells were examined. The levels of ROS were markedly increased $(\mathrm{P} \leq 0.0001)$ following the combined treatment with VPA/MG132, VPA/PI-1 and VPA/PR-39 compared to the untreated cells and cells treated with VPA or PIs alone (Fig. 2C). Additionally, solo treatments with MG132 ( $\mathrm{P} \leq 0.0001)$ or PI-1 $(\mathrm{P} \leq 0.004)$ significantly induced ROS generation, compared to the untreated cancer cells. The induction of ROS was abrogated by pre-treatment with L-NAC (data not shown).

Alterations in the cell cycle and induction of apoptosis in colorectal cancer cells treated with VPA, PIs or a combination of both. To elucidate the effects of VPA, the tested PIs, and the combinations of VPA with each PI on the cell cycle, the distribution of cancer cells in the various cell cycle phases $\left(\mathrm{G}_{0} / \mathrm{G}_{1}, \mathrm{~S}\right.$ and $\left.\mathrm{G}_{2} / \mathrm{M}\right)$ was determined by flow cytometry. Treatment of the SW837 cancer cells with VPA resulted in the accumulation of cancer cells in the S phase [63.6 vs. $44.3 \%$ for the untreated cells (UT)] at the expense of a strong decrease in the number of cells in the $\mathrm{G}_{0} / \mathrm{G}_{1}$ phase ( 31.9 vs. $41.5 \%$ for UT) and the $\mathrm{G}_{2} / \mathrm{M}$ phase (4.4 vs. $14.1 \%$ for UT) (Fig. 3A).

Treatment of the SW837 cells with PR-39 resulted in a marked accumulation of cancer cells in the $\mathrm{S}$ phase 
A
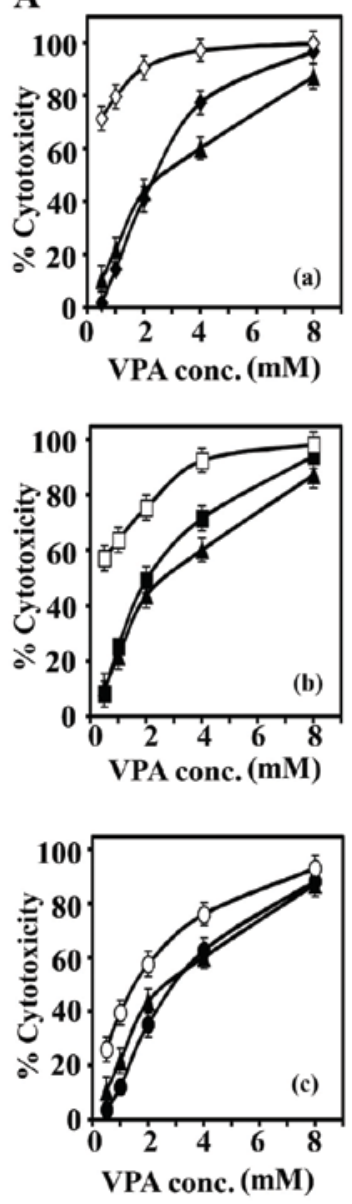
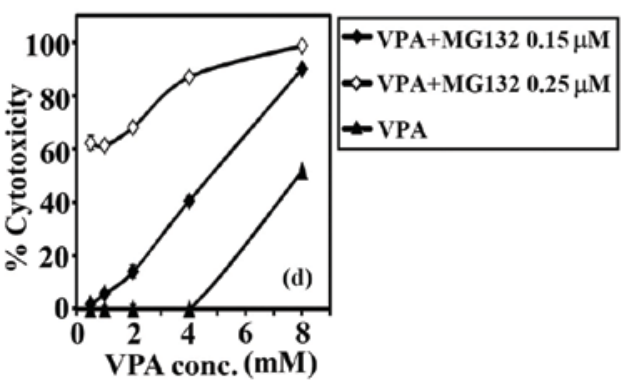

(d)
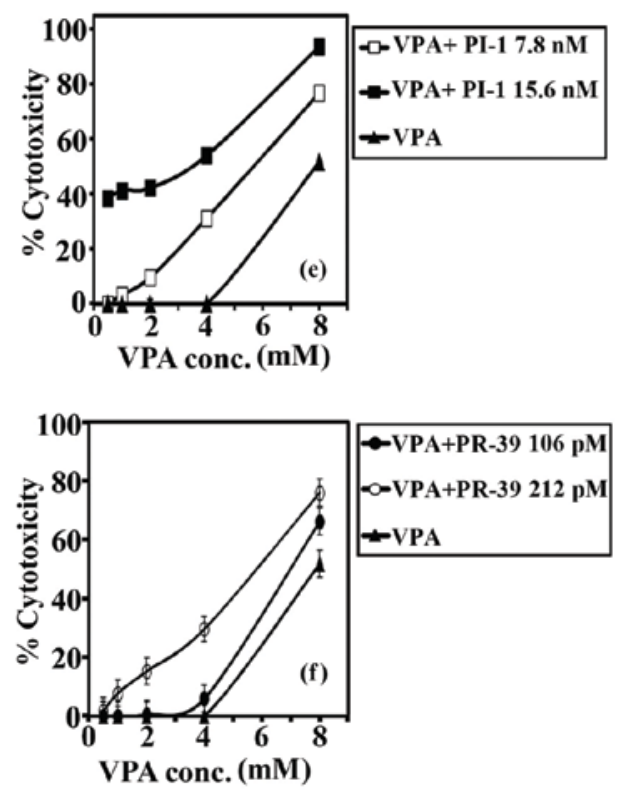
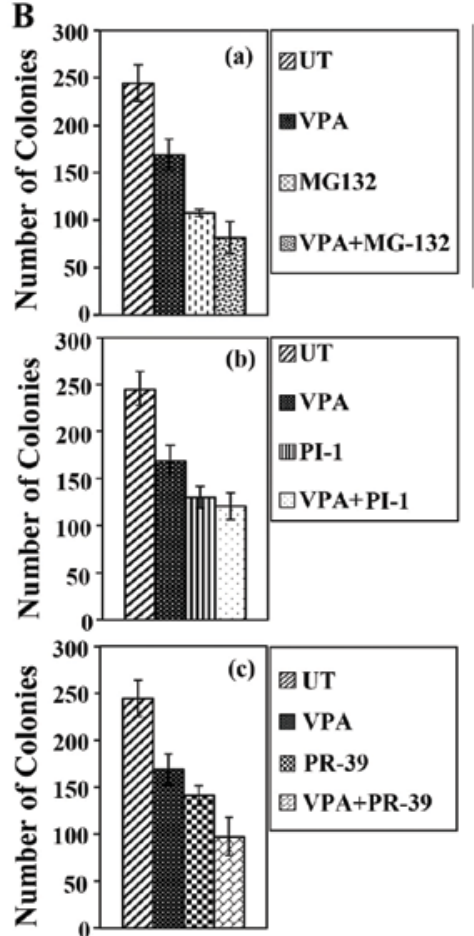

Human colorectal cancer cell line SW1116

C

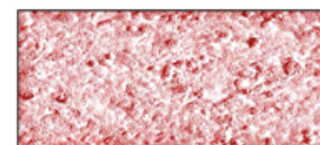

(a) UT

(b) VPA

(c) PR-39

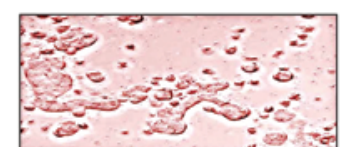

(d) VPA+MG-132

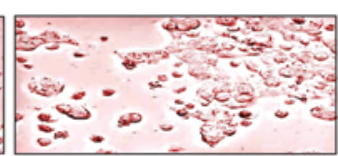

(e) VPA+PI-1

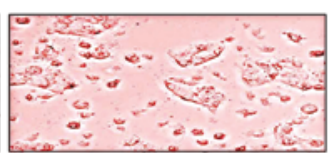

(f) VPA+PR-39

Figure 1. Potentiation of the antimitogenic activity of the histone deacetylase inhibitor (HDACI), valproic acid (VPA), against human colorectal cancer cells by combination with proteasome inhibitors (PIs). (A) Inhibition of colorectal cancer cell growth. (a-c) SW1116 and (d-f) SW837 cells were treated with various concentrations of VPA (0.5-8.0 mM) for $24 \mathrm{~h}$ followed by treatment with the PIs, MG132 (0.15 and $0.25 \mu \mathrm{M})$, PI-1 (7.8 and $15.6 \mathrm{nM})$ and PR-39 (106 and $212 \mathrm{pM}$ ) for $72 \mathrm{~h}$. Control cells were treated with the vehicle (DMSO) at a final concentration of $0.2 \%$. (B) Inhibition of colony formation. Untreated and treated cells were trypsinized, counted and inoculated $(5,000$ cells $/ \mathrm{ml})$ into 6-well plates and incubated for 10-14 days. Cells were then fixed in $100 \%$ methanol for $30 \mathrm{~min}$ at room temperature and stained for $1 \mathrm{~h}$ with $0.1 \%$ crystal violet. The stained colonies were counted and compared with an untreated control sample. (C) Morphological changes of cancer cells treated with VPA, PIs and a combination of VPA with each PI. VPA conc., concentration of VPA.

( 74.7 vs. $44.3 \%$ for UT) at the expense of a decrease in the number of cells in the $\mathrm{G}_{0} / \mathrm{G}_{1}$ phase (23.9 vs. $41.5 \%$ for UT) and the $\mathrm{G}_{2} / \mathrm{M}$ phase (1.3 vs. $14.1 \%$ for UT) (Fig. 3A). Treatment of the SW837 with MG132 or PI-1 resulted in the growth arrest of cancer cells in the $S$ phase or the $G_{0} / G_{1}$ phase, respectively (data not shown).

Combined treatment with VPA and MG132 arrested the growth of the cancer cells in the S phase (69.7 vs. $44.3 \%$ for UT) at the expense of a decrease in the number of cells in the $G_{0} / G_{1}$ phase (23.2 vs. $41.5 \%$ for $\left.U T\right)$ and $G_{2} / M$ phase (6.9 vs. $14.1 \%$ for UT) (Fig. 3A).

Treatment with a combination of VPA and PI-1 resulted in the accumulation of SW837 cells in the S phase (71.6 vs. $44.3 \%$ for UT) at the expense of a decrease in cells in the $\mathrm{G}_{0} / \mathrm{G}_{1}$ phase (27.6 vs. $41.5 \%$ for $U T$ ) and the $\mathrm{G}_{2} / \mathrm{M}$ phase $(0.77$ vs. $14.1 \%$ for UT) (Fig. 3A).

Combined treatment with VPA and PR-39 resulted in the accumulation of cancer cells in the $S$ phase (66.7 vs. $44.3 \%$ 
A
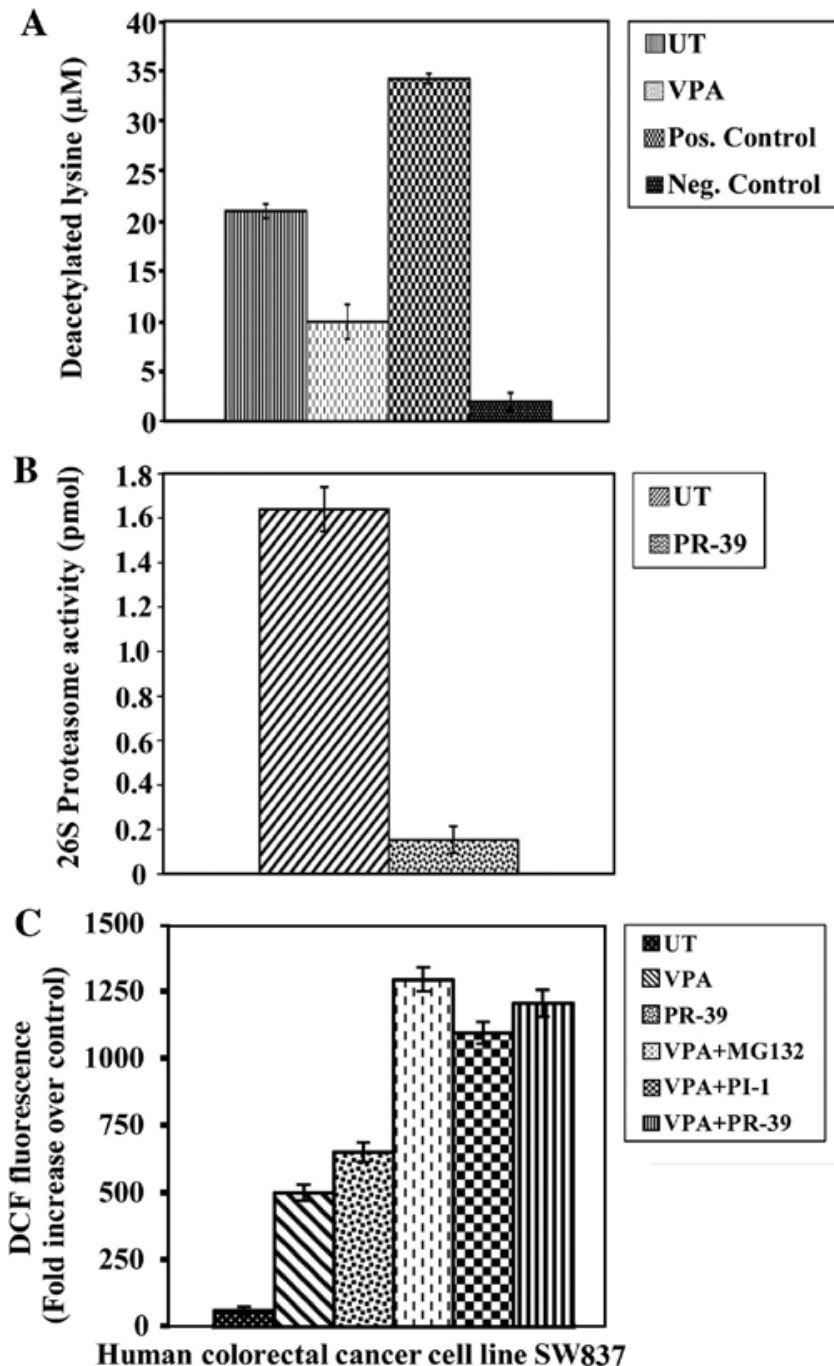

Figure 2. Histone deacetylase (HDAC) and proteasome activities, and the generation of reactive oxygen species (ROS) in colorectal cancer cells treated with valproic acid (VPA), proteasome inhibitors (PIs) and their combinations. SW837 cells were seeded $\left(2.5 \times 10^{5}\right.$ cells/well $)$ into 24 -well plates and incubated at $37^{\circ} \mathrm{C}$ for $18 \mathrm{~h}$. Cells were treated with VPA $(2.5 \mathrm{mM})$ and the PIs, MG132 $(1.5 \mu \mathrm{M})$, PI-1 (36 nM), PR-39 $(2 \mathrm{nM})$, or a combination of VPA and PIs for $24 \mathrm{~h}$. (A) HDAC, (B) $26 \mathrm{~S}$ proteasome activities and (C) reactive oxygen species (ROS) generation were monitored in untreated (UT) and treated cancer cell extracts as described in Materials and methods.

for UT) at the expense of a decrease in the $\mathrm{G}_{0} / \mathrm{G}_{1}$ phase (31 vs. $41.5 \%$ for UT) and the $\mathrm{G}_{2} / \mathrm{M}$ phase (2.2 vs. $14.1 \%$ for UT) (Fig. 3A). In a parallel experiment of the distribution of the cell cycle phase using the SW1116 colorectal cancer cells treated with VPA, PIs, or a combination of VPA with PIs, the results obtained were similar to those obtained with the SW837 cells (data not shown).

To determine what effect, if any, the PIs (MG132, PI-1 and PR-39) exert on the response of colorectal cancer cells to VPA and to distinguish between the different types of cell death, untreated and treated SW837 cells were double-stained with Annexin V and propidium iodide and analyzed by flow cytometry. Annexin V binding combined with PI labeling was performed for the distinction between apoptosis (Annexin $\mathrm{V}^{+} /$propidium iodide) and necrosis (Annexin $\mathrm{V}^{+} /$propidium iodide ${ }^{+}$).
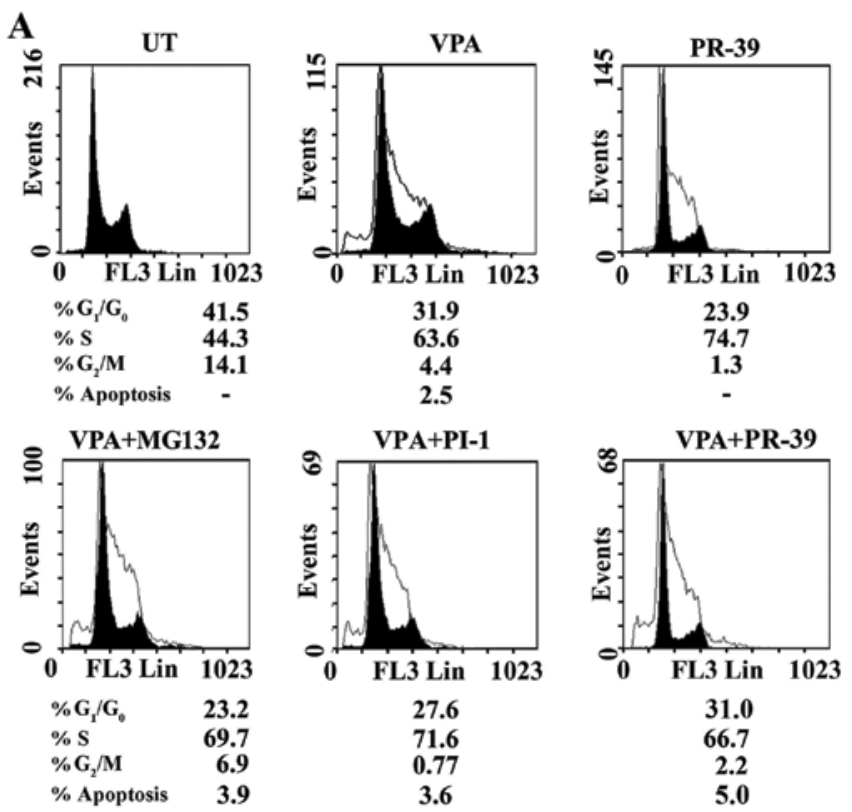

B
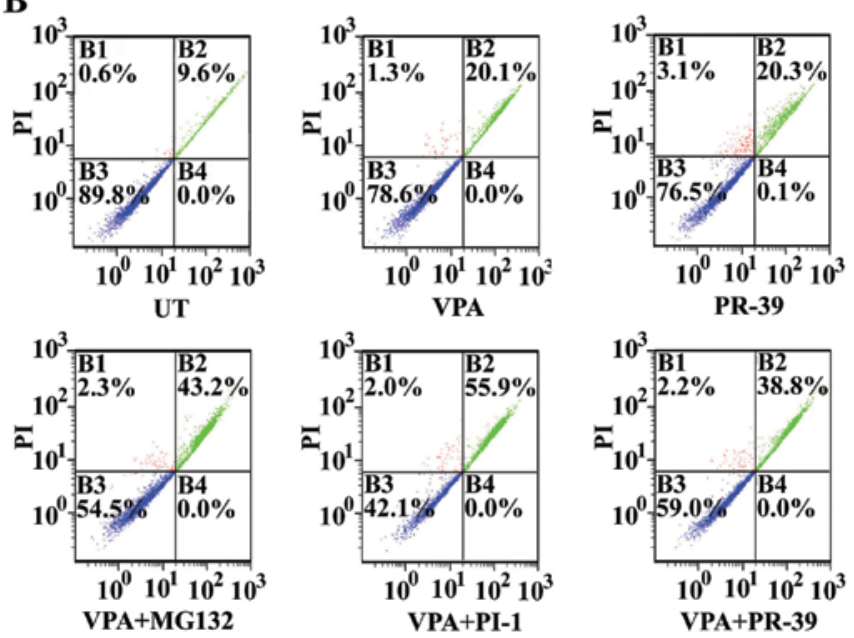

Figure 3. Modulation of cell cycle and induction of apoptosis in colorectal cancer cells treated with valproic acid (VPA), proteasome inhibitors (PIs) and their combinations. (A) Cell cycle analysis: SW837 cells $\left(2.5 \times 10^{5}\right.$ cell $\left./ \mathrm{ml}\right)$ were treated with VPA $(2.5 \mathrm{mM})$ and the PIs, MG132 $(1.5 \mu \mathrm{M}), \mathrm{PI}-1$ (36 nM) or PR-39 $(2 \mathrm{nM})$, and a combination of both for $24 \mathrm{~h}$ : at least 3 samples were analyzed and 20,000 events were scored for each sample. The vertical axis represents the relative number of events and the horizontal axis represents the fluorescence intensity. (B) Monitoring of apoptosis. SW837 cells were treated as described above. Cells were stained with Annexin V-fluorescein and propidium iodide, and then analyzed by flow cytometry. Quadrant B1, percentage of necrotic cells; quadrant B2, percentage of late apoptotic cells; quadrant B3, percentage of living cells; and quadrant B4, percentage of early apoptotic cells.

Treatment of the SW837 cancer cells with the combination of VPA and MG132 markedly induced apoptosis $(0.0 \%$ early apoptosis, $43.2 \%$ late apoptosis, and $2.3 \%$ necrosis) compared to the untreated cells $(0.0 \%$ early apoptosis, $9.6 \%$ late apoptosis and $0.6 \%$ necrosis), VPA alone-treated SW837 cells $(0.0 \%$ early apoptosis, $20.1 \%$ late apoptosis, and $1.3 \%$ necrosis) (Fig. 3B) and the MG132 alone-treated SW837 cells $(0.0 \%$ early apoptosis, $26.4 \%$ late apoptosis and $0.8 \%$ late apoptosis) (data not shown). 
In addition, the combination of VPA and PI-1 markedly induced the apoptosis of SW837 cells $(0.0 \%$ early apoptosis, $55.9 \%$ late apoptosis, and $2.0 \%$ necrosis) compared to the untreated SW837 cells (0.0\% early apoptosis, $9.6 \%$ late apoptosis, and $0.6 \%$ necrosis) and the SW837 cells treated with VPA alone ( $0.0 \%$ early apoptosis, $20.1 \%$ late apoptosis, and $1.3 \%$ necrosis) or the PI-1 alone-treated SW837 cells $(0.0 \%$ early apoptosis, $11.9 \%$ late apoptosis, and $0.8 \%$ necrosis) (data not shown). Moreover, the combined treatment of the SW837 cancer cells with VPA and PR-39 markedly enhanced apoptosis $(0.0 \%$ early apoptosis, $38.8 \%$ late apoptosis and $2.2 \%$ necrosis) compared to the untreated, VPA-treated and PR-39 alone-treated SW837 cells (0.1\% early apoptosis, $20.3 \%$ late apoptosis and $3.1 \%$ necrosis) (Fig. 3B).

These results suggested that the tested PIs, MG132, PI-1 and PR-9, markedly increased VPA-mediated lethality in human colorectal cancer cells. The induction of apoptosis in the SW1116 colorectal cancer cells treated with VPA, PIs or a combination of both provided similar results to those obtained with SW837 (data not shown).

Expression of Bax, cytochrome $c, N F-\kappa B, p-A k t, p-E R K 1 / 2$ and $p-J N K$ in colorectal cancer cells treated with VPA, PI-1 or their combination. A previous study, using several models of apoptosis demonstrated that Bax translocates from the cytosol to the mitochondria when overexpressed or in response to certain cell death stimuli. Moreover, the translocation of Bax to the mitochondria in a number of systems has been suggested to be responsible for the release of cytochrome $c$ from the mitochondria to the cytosol and the activation of apoptosis (16). In this study, to examine whether this pathway was activated by combined treatment with VPA and PI-1, the effects of single and combined treatment with VPA and PI-1 on Bax translocation and cytochrome $c$ release were examined. The SW837 cells treated with VPA, PI-1 or the combination of both were collected and separated into cytosolic and mitochondrial fractions. The distributions of Bax and cytochrome $c$ in these fractions were examined by western blot analysis. Elevated levels of Bax were detected in the mitochondria following combined treatment with VPA and PI-1, concomitant with the decrease in Bax expression in the cytosolic fraction (Fig. 4A and E). A marked increase in cytochrome $c$ release in the cytosolic fraction corresponded with a decrease in cytochrome $c$ release in the mitochondrial fraction (Fig. 4B and F). These results suggested that the combined treatment with VPA and PI-1 induced the translocation of Bax to the mitochondria, subsequently releasing cytochrome $c$, preferentially into the cytosol of the SW837 colorectal cancer cells.

The NF- $\mathrm{B}$ pathway is a key pathway that promotes the expression of proliferative and anti-apoptotic genes. The functions of NF- $\kappa B$ depend on its cellular distribution (17). In this study, to determine whether $\mathrm{NF \kappa B}$ is involved in the synergistic apoptotic effects of VPA and PI-1, the alterations in NF- $\kappa \mathrm{B}$ distribution in the SW837 cells were examined. Treatment with VPA or PI-1 alone had little effect on cytoplasmic NF- $\mathrm{B}$ expression compared to the untreated cells, although nuclear NF- $\kappa \mathrm{B}$ expression was slightly increased (Fig. 4C). Despite the elevated level of $\mathrm{NF}-\kappa \mathrm{B}$ observed in the cytoplasm of the colorectal cancer cells, following co-treatment with VPA and
PI-1, there was a marked decrease in the amount of nuclear $\mathrm{NF}-\kappa \mathrm{B}$ (Fig. 4C and G). These data clearly indicate that the combination of VPA and PI-1 affects the nuclear translocation of NF- $\kappa \mathrm{B}$ in colorectal cancer cells, suggesting that the dysfunction of $N F-\kappa B$ is involved in the synergistic apoptotic effects of VPA and PIs.

To further elucidate the underlying molecular mechanisms of the anticancer effects of VPA, PIs or the combination of VPA with PIs on human colorectal cancer cells, the expression of pro-survival-related (p-Akt and p-ERK1/2) and stressrelated ( $\mathrm{p}-\mathrm{JNK}$ ) genes was examined by western blot analysis. As shown in Fig. 4D, there was a slight decrease in p-Akt and p-ERK1/2 expression in the SW837 cells following treatment with VPA or PI-1 alone. More importantly, co-treatment with VPA and PI-1 induced a marked reduction in the levels of p-Akt and p-ERK1/2. On the other hand, p-JNK levels were slightly increased in the cancer cells treated with either VPA or PI-1 alone, while co-treatment with both VPA and PI-1 markedly increased the levels of p-JNK (Fig. 4D and H). These data suggest that the Akt, ERK1/2 and JNK pathways are associated with the enhanced apoptosis that is induced by the combination of VPA and PIs.

mRNA expression of genes involved in the regulation of the cell cycle and apoptosis in colorectal cancer cells treated with VPA, PIs or a combination of both. To elucidate the molecular mechanisms responsible for the increased lethality induced by VPA in the human colorectal cancer cells following combination treatment with PIs, the effects of co-treatment with VPA and PIs on the expression/activation of various signaling molecules were examined. Treatment of the SW837 cells with a combination of VPA and MG132, PI-1 or PR-39 markedly downregulated the mRNA expression of genes related to cell cycle control, CDK1, CDK4 and CDC25A, compared to treatment with VPA, PR-39 (Fig. 5A), MG132 or PI-1 alone (data not shown). By contrast, the same combined treatments upregulated the mRNA expression of the p15, p19, p21 and p27 genes, compared to treatment with only one agent (Fig. 5A).

Treatment of the SW837 cells with a combination of VPA and PIs differentially upregulated the mRNA expression of the pro-apoptotic genes, Bax, Bad, Bim, Apaf1, and caspase-3, -8 and -9 . However, the same combined treatment differentially downregulated the expression of the anti-apoptotic genes, Bcl-2, XIAP and FLIP, (Fig. 5B). The cycle threshold values $(\mathrm{Ct})$ of the target genes under investigation in this study ranged from 20.826-30.981.

Chemosensitization of human colorectal cancer cells by combined treatment with VPA and PIs. The ability of the combined treatments with VPA and PIs, MG132, PI-1 or PR-39 to sensitize the cancer cells to standard chemotherapeutic drugs was examined. The results are summarized in Figs. 6-10 and Tables I and II.

The combination of VPA and MG132 exhibited a potent chemosensitizing effect on the SW837 colorectal cancer cells to CPT (46-fold), 5FU (330-fold), DOX (376-fold), TAX (75-fold), ETP (188-fold), AMS (104-fold) and HHG (40-fold). The same combination of VPA and MG132 enhanced the chemosensitivity of the SW1116 colorectal cancer cells to CPT (29-fold), 5FU (41-fold), ETP (140-fold) and AMS 
A Bax

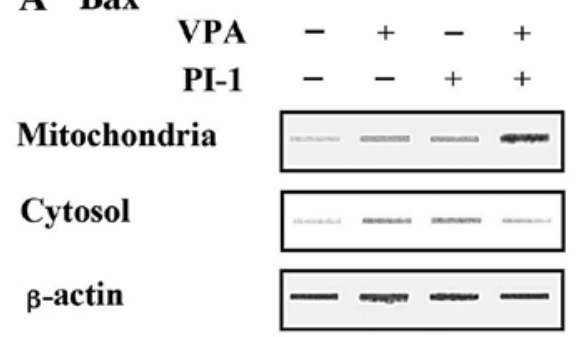

B Cytochrome c

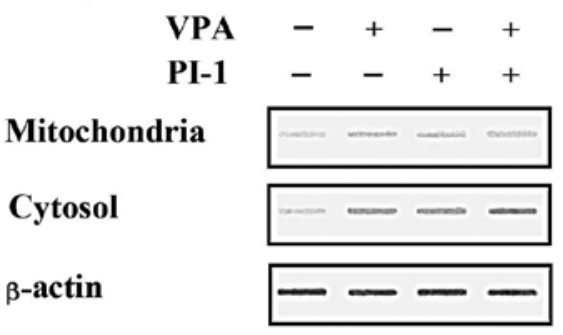

C NF-kB (p65)

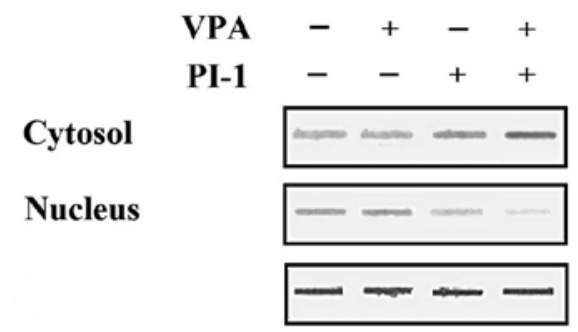

$\mathbf{E}$

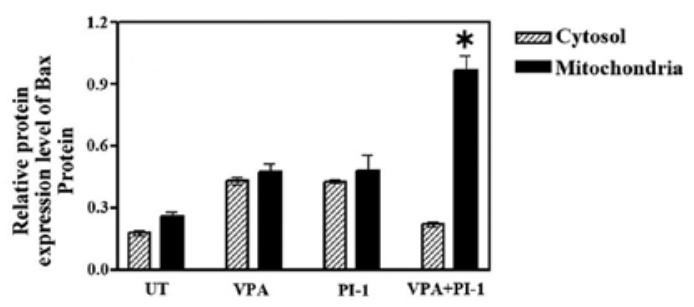

F

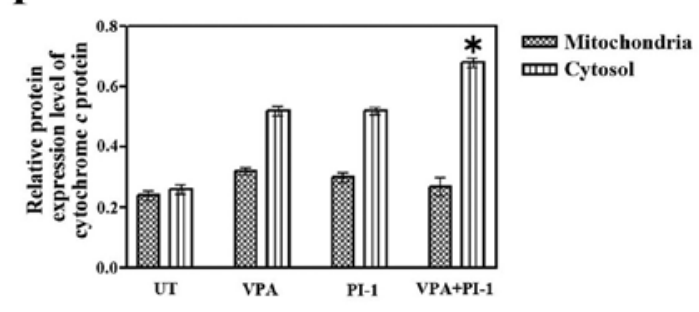

G

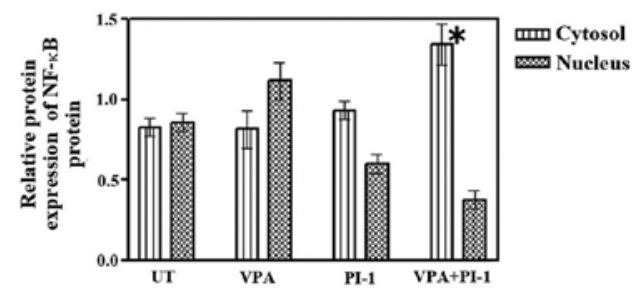

D Prosurvival and stress-related proteins

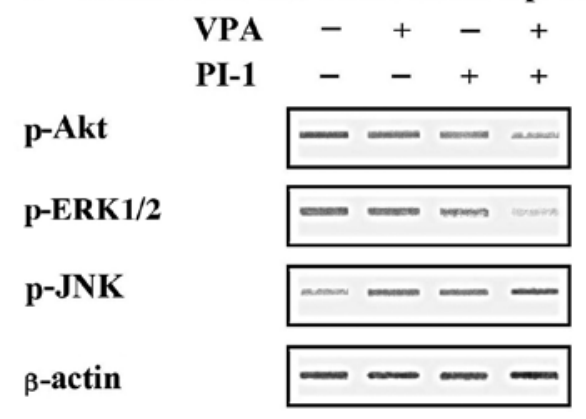

$\mathbf{H}$

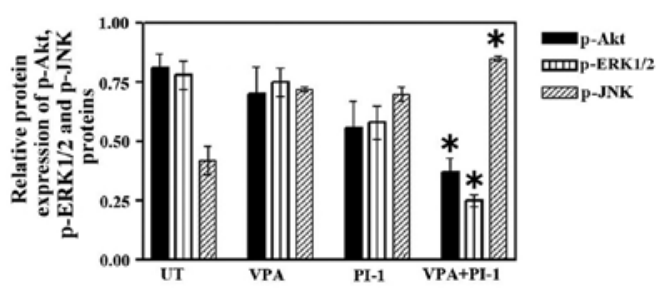

Figure 4. Effect of valproic acid (VPA), proteasome inhibitor-1 (PI-1) or their combination on Bax translocation, cytochrome $\mathrm{c}$ release and nuclear factor- $\mathrm{B}$ $(\mathrm{NF}-\mathrm{kB})$, phospho-Akt (p-Akt), phospho-extracellular signal-regulated kinase 1/2 (p-ERK1/2), as well as phospho-c-Jun N-terminal kinase (p-JNK) signaling pathways in cancer cell extracts after solo or combined treatment with VPA and PI-1. SW837 cells $\left(2.5 \times 10^{5}\right.$ cells/well) were plated into $24-$ well plate and incubated at $37^{\circ} \mathrm{C}$ for $18 \mathrm{~h}$. Cells were then treated with VPA $(2.5 \mathrm{mM})$, PI-1 (36 nM) or their combination for $24 \mathrm{~h}$. Cytosolic, mitochondrial and nuclear fractions were prepared as described in Materials and methods. (A) Translocation of Bax from the cytosol to the mitochondria, (B) cytochrome $c$ release from the mitochondria to the cytosol, (C) the levels of NF- $\mathrm{BB}$ in the nucleus and (D) cytoplasmic fractions and the levels of p-Akt, p-ERK1/2 and p-JNK were analyzed by western blot analysis. Relative protein expression of (E and F) mitochondrial and cytosolic Bax and cytochrome $c$, of (G) cytoplasmic and nuclear NF- $\kappa \mathrm{B}$, of $(\mathrm{H}) \mathrm{p}$-Akt, p-ERK and p-JNK after normalization to $\beta$-actin, ${ }^{*} \mathrm{P}<0.05$ vs. control (untreated cells). Data were obtained from at least 3 replicate experiments.

(31-fold). Moreover, the combination of VPA and PI-1 markedly increased the chemosensitivity of the SW1116 colorectal cancer cells to CPT (138-fold), 5FU (185), DOX (42-fold), ETP (170-fold) and HHG (53-fold). This combination exerted a more profound chemosensitizing effect on the SW837 colorectal cancer cells to CPT (96-fold), 5FU (620-fold), DOX (312-fold), TAX (109-fold), ELP (187-fold), AMS (405-fold) and HHG (93-fold) compared to that observed in the SW1116 colorectal cancer cells. Furthermore, the combination of VPA and PR-39 exhibited a marked enhancement in the chemosensitivity of the SW837 colorectal cancer cells to CPT (54-fold), 5FU (40-fold), DOX (38-fold), ETP (36-fold), ELP (47-fold) and AMS (16-fold), compared to the SW1116 colorectal cancer cells (Tables I and II).

Collectively, these results clearly indicate the potential of the combined treatment with VPA and the PIs, MG132, PI-1 
A Cell cycle - related gemes
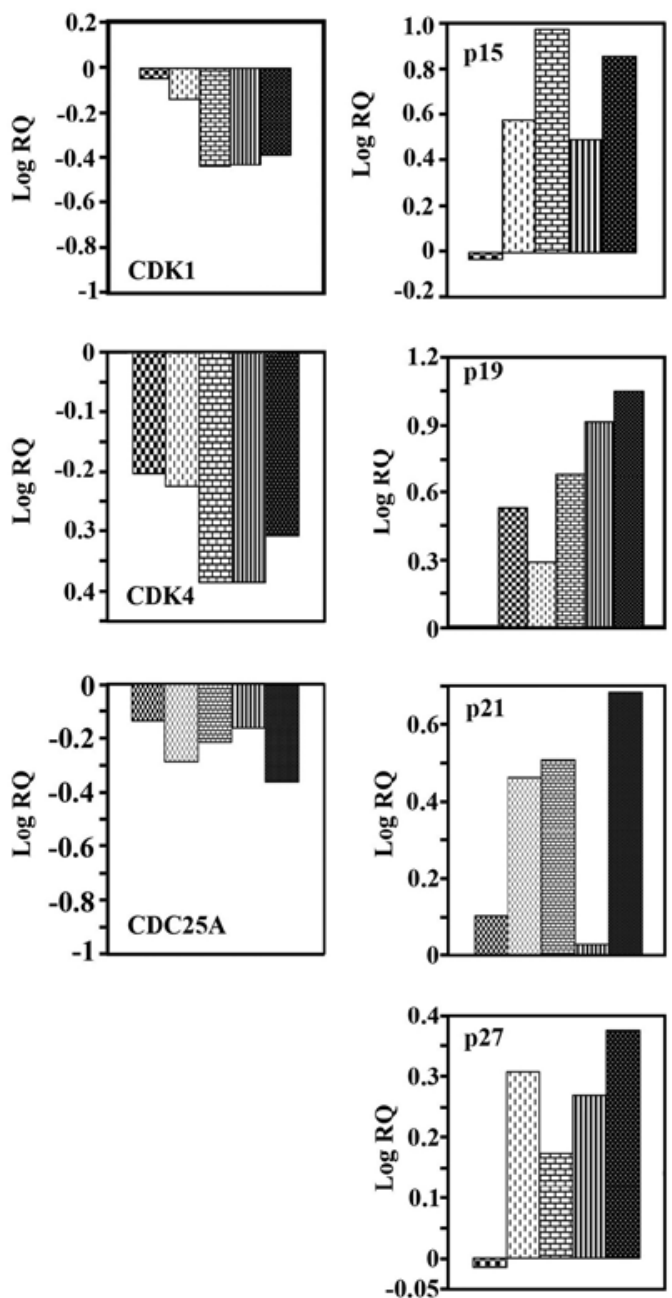

Human colorectal cancer cell line SW837

\section{B Apoptosis - related genes}
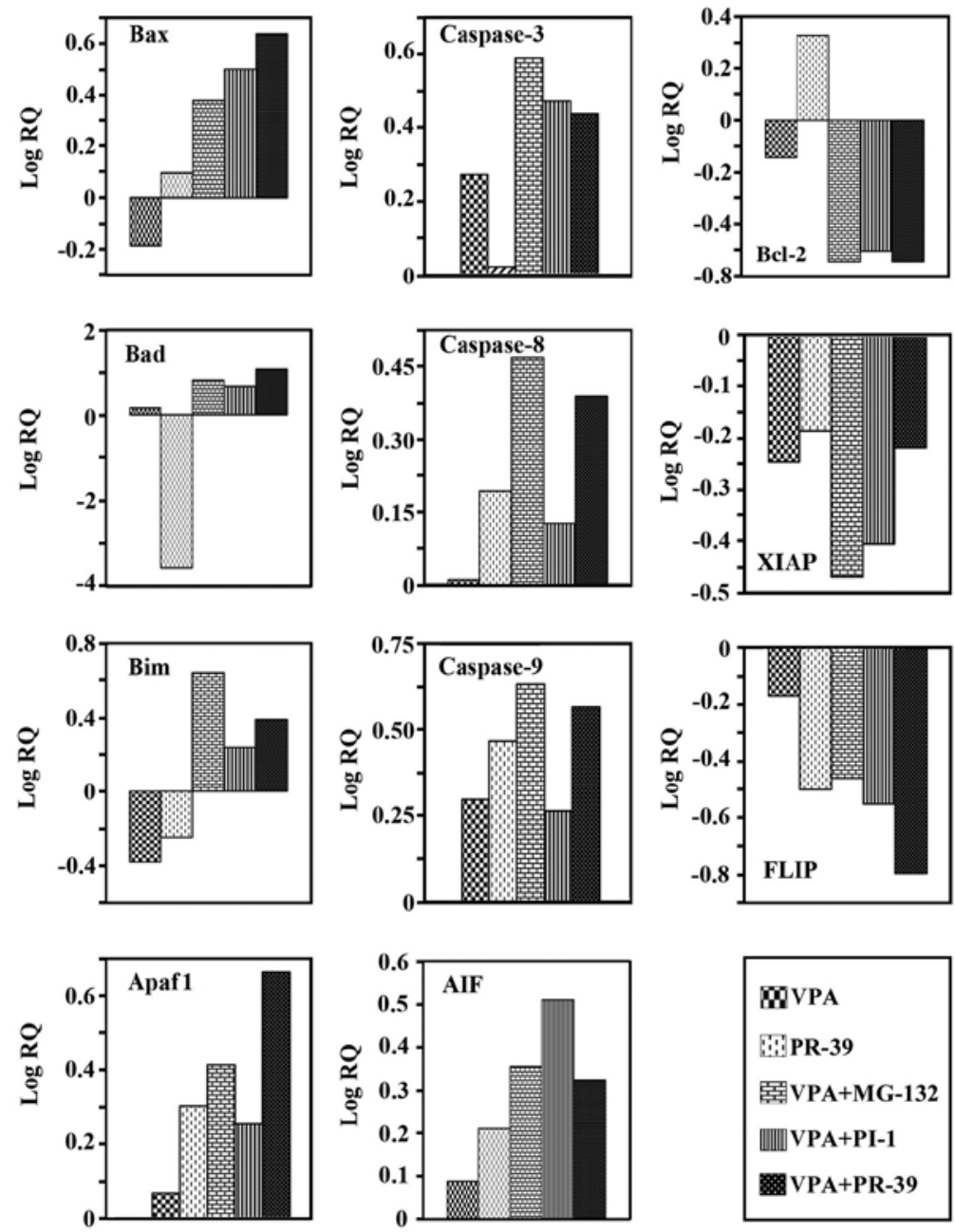

Human colorectal cancer cell line SW 837

Figure 5. mRNA expression of cell cycle- and apoptosis-related genes in colorectal cancer cells treated with valproic acid (VPA), proteasome inhibitor-1 (PI-1) and the combination of the two agents. SW837 cells $\left(2.5 \times 10^{5}\right.$ cell/ml) were treated with VPA (2.5 mM) and the PIs, MG132 (1.5 $\mu$ M), PI-1 (36 nM) or PR-39 $(2 \mathrm{nM})$, or their combination for $24 \mathrm{~h}$. Expression of genes controlling the cell cycle or apoptosis was determined by measuring the mRNA levels by RT-PCR and $\mathrm{qPCR}$ and the comparative $\Delta \Delta \mathrm{Ct}$ method. The amount of the target, normalized to an endogenous reference and relative to a calibrator, is given as $2^{-\Delta \Delta \mathrm{Ct}}$.

and PR-39, to significantly enhance the chemosensitivity of colorectal cancer cells to standard chemotherapeutic drugs. This combined effect is exerted through various mechanisms of action in a combination- and cancer subtype-dependent manner. The effect of the combined treatment with VPA/ MG132, VPA/PI-1 and VPA/EPM on normal human fibroblast cells CRL1545 was also examined microscopically by an MTT assay. The results presented in Fig. 10B clearly demonstrate that these combinations have little effect $(\leq 10-15 \%)$ on CRL 1554 cells, indicating their minimal cytotoxicity.

\section{Discussion}

VPA, a branched short-chain fatty acid, is widely used as an anti-epileptic drug and a mood stabilizer. VPA was classified as an HDACI, acting at the level of gene transcription by inhibiting deacetylation and making transcription sites more accessible (18). Due to the increasing number of clinical trials involving VPA, and the interesting results obtained from such studies, we hypothesize that this molecule will be involved in an increasing number of therapies in the near future. Nevertheless, numerous publications related to the therapeutic effects of VPA have also indicated the possible side-effects associated with its use in treatment $(19,20)$. Favoring the advantageous effects of VPA use by balancing the therapeutic potential with serious side-effects will no doubt prove to be a challenging and complex issue in clinical management (20). The enhanced effectiveness of VPA against cancer may be achieved by combining VPA treatment with agents that have different modes of action and diverse targets, such as PIs. Few studies have focused on the therapeutic potential of VPA in human colorectal cancer (21). In the present study, we examined the effectiveness of combining HDAC inhibition via VPA with proteasome inhibition via MG132, PI-1 or PR-39 on colorectal cancer cell lines, with regard to their potential synergistic effects on cell proliferation and apoptosis. We also investigated the synergistic molecular mechanisms of the combined treatment by assessing the effects on pro-survival- 
A

SW1116, chemosensitization with VPA/MG132
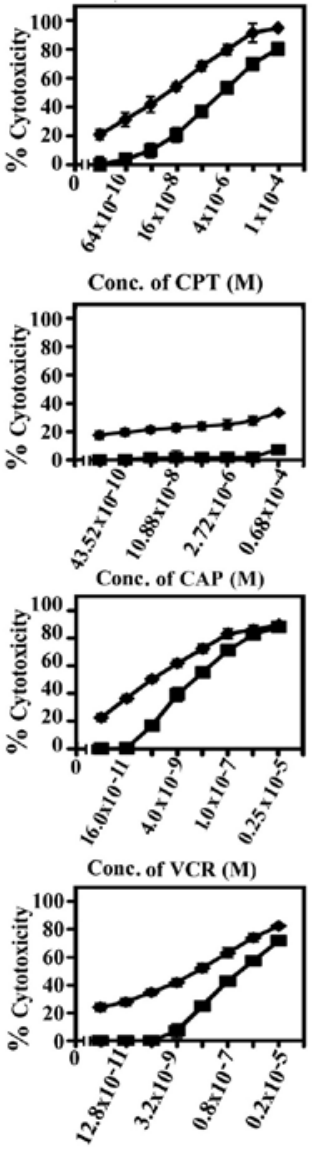

Conc. of HHG (M)
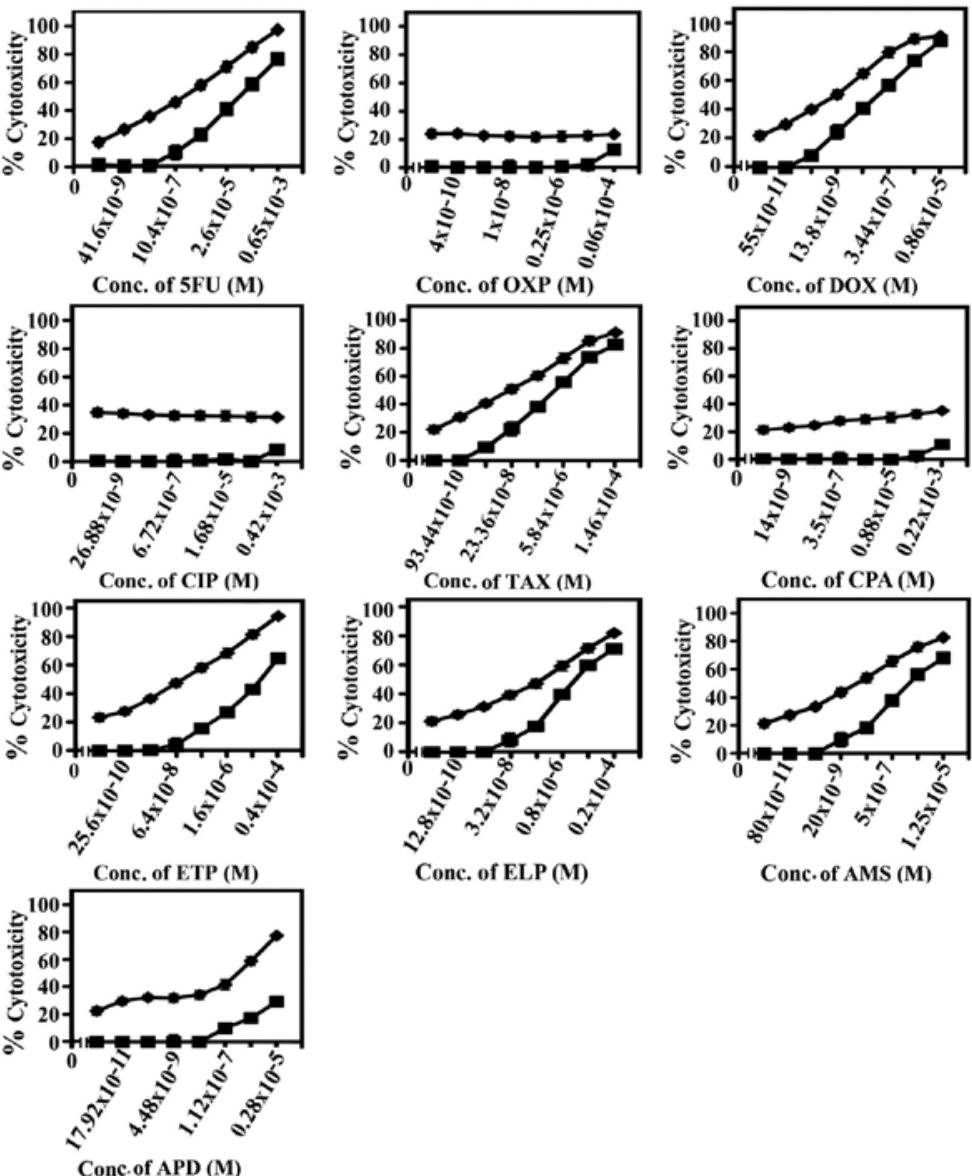

Conc. of ELP (M)

Conc. of AMS (M)

B SW1116, chemosensitization with VPA/PI-1

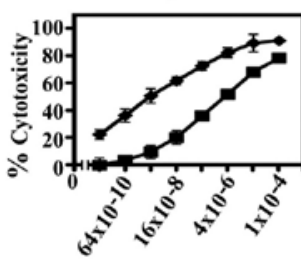

Conc. of CPT (M)

A

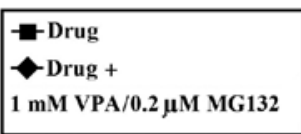

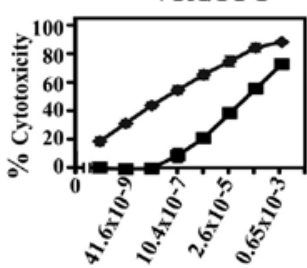

Conc. of $5 F U$ (M)

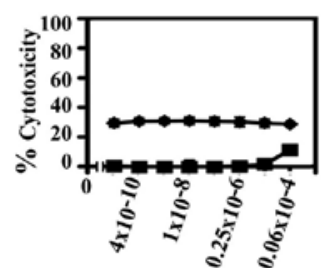

Conc. of OXP (M)

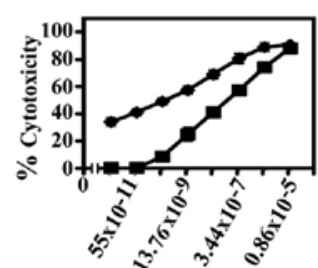

Conc. of DOX (M)

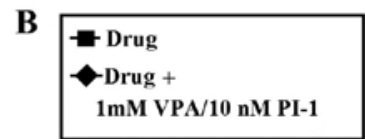

Figure 6. Chemosensitizing effect of combined treatment with valproic acid (VPA) and MG132 or proteasome inhibitor-1 (PI-1) on SW1116 colorectal cancer cells. Cancer cells were inoculated $\left(27 \times 10^{3}\right.$ cells/well) into 96 -well plates and allowed to grow for $18 \mathrm{~h}$. The cells were treated with various concentrations of (A) camptothecin (CPT), 5FU, oxaliplatin (OXP), doxorubicin (DOX), carboplatin (CAP), cisplatin (CIP), taxol (TAX), cyclophosphamide (CPA), vincristine (VCR), etoposide (ETP), ellipticine (ELP), amsacrine (AMS), homoharringtonine (HHG) and aphidicolin (APD) or (B) CPT, 5-fluorouracil (5FU), OXP and DOX for $24 \mathrm{~h}$. The drugs were then removed, cells washed with HBSS and treated with a combination of (A) VPA (1.0 mM)/MG132 (0.2 $\mu$ M) or (B) VPA $(1.0 \mathrm{mM}) / \mathrm{PI}-1(10 \mathrm{nM})$ for $72 \mathrm{~h}$. Cell proliferation was monitored by MTT assay. conc., concentration.

and stress-related gene expression, and the potential of the combined treatments to sensitize the human colorectal cancer cells to standard chemotherapeutic drugs.

In the present study, combined treatment with VPA and the PIs, MG132, PI-1 or PR-39, markedly decreased the survival of human colorectal cancer cells when compared to treatment with VPA or any of the tested PIs alone (Fig. 1). MG132 $(0.25 \mu \mathrm{M})$ markedly enhanced the sensitivity of the SW1116 cells (SR 6.75) (Fig. 1A-a and d) and the SW837 cells ( $\mathrm{IC}_{80} 3 \mathrm{mM}$ for combined treatment vs. $\mathrm{IC}_{50}=7.5 \mathrm{mM}$ for VPA alone) to VPA. PI-1 $(7.8 \mathrm{nM})$ moderately increased the sensitivity of the SW1116 cells (SR 1.5) and SW837 cells (SR 1.3), and at $15.6 \mathrm{nM}$, PI-1 further enhanced the sensitivity of the SW1116 cells (SR 3.3) and the SW837 cells (SR 2.1) to VPA (Fig. 1A-b and e). Furthermore, PR-39 (106 pM) slightly increased the sensitivity of the SW1116 cells (SR 1.33) and SW837 cells (SR 1.15) to VPA. PR-39 at a concentration of $212 \mathrm{pM}$ moderately enhanced the sensitivity of the SW1116 cells (SR 2.4) and the SW837 cells (SR 1.4) to VPA (Figs. 1A-c and f). The results of the experiments on the inhibitory effects were confirmed by the observation of inhibi- 
A SW1116, chemosensitization with VPA / PI-1
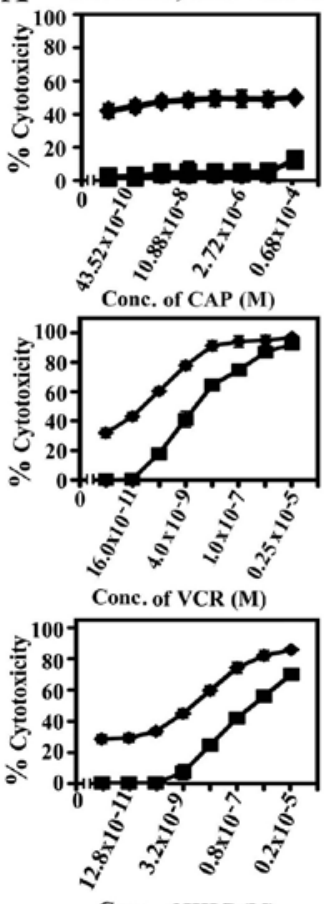

Conc. of HHG (M)
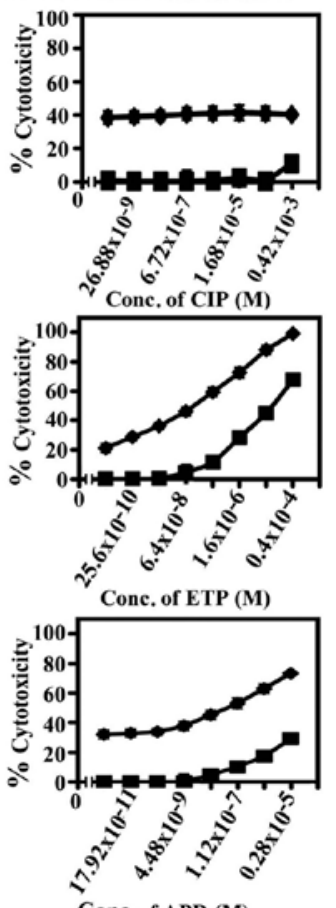

Conc. of APD (M)

B SW1116, chemosensitization with VPA / PR-39
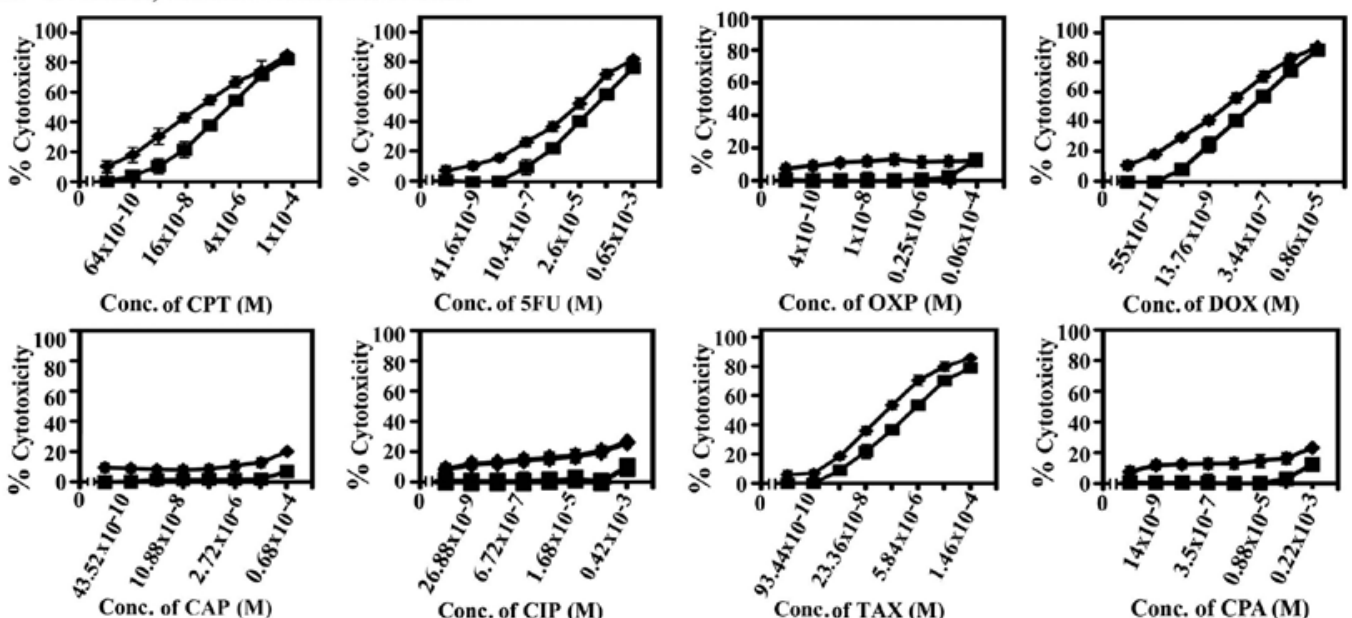

A
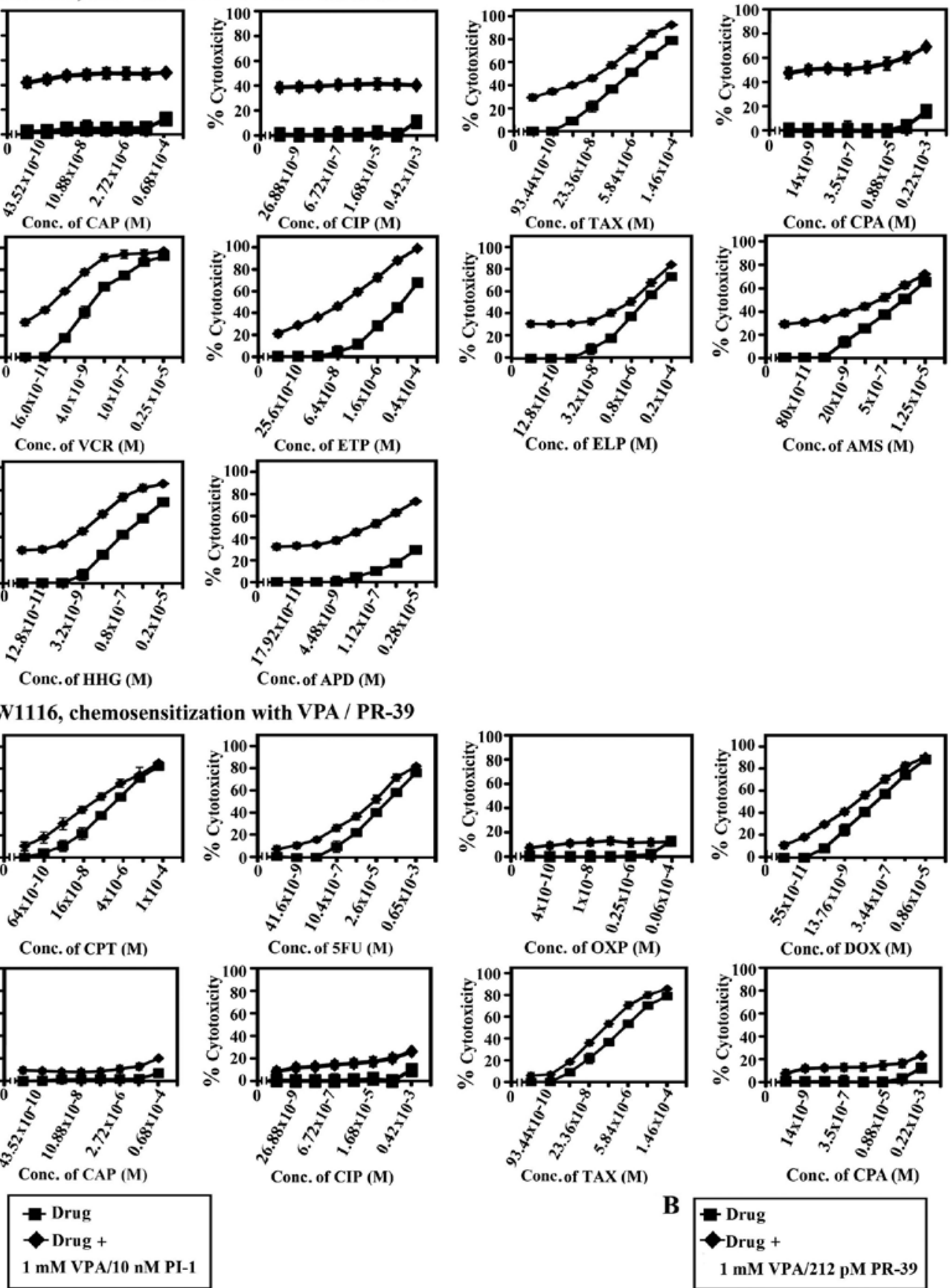

Conc. of AMS (M)
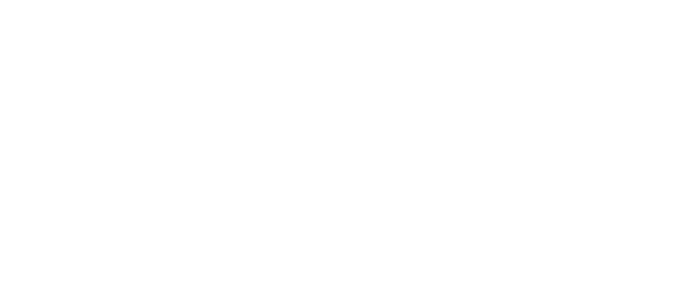

B

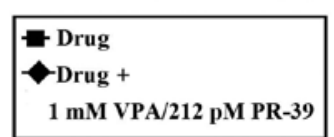

Figure 7. Chemosensitizing effect of combined treatment with valproic acid (VPA) and proteasome inhibitor-1 (PI-1) or PR-39 on SW1116 colorectal cancer cells. SW1116 cells were seeded $\left(27 \times 10^{3}\right.$ cells/well) into 96 -well plates and incubated for $18 \mathrm{~h}$. Cells then were treated with various concentrations of (A) carboplatin (CAP), cisplatin (CIP), taxol (TAX), cyclophosphamide (CPA), vincristine (VCR), etoposide (ETP), ellipticine (ELP), amsacrine (AMS), homoharringtonine (HHG) and aphidicolin (APD) or (B) camptothecin (CPT), 5 -fluorouracil (5FU), oxaliplatin (OXP), doxorubicin (DOX), CAP, CIP, TAX, CPA for $24 \mathrm{~h}$. The drugs were then removed, cells washed with HBSS and treated with a combination of VPA (1.0 mM)/PI-1 (10 nM) (A) or VPA (1.0 mM)/ PR-39 (212 pM) for 72 h. Cell proliferation was monitored by MTT assay. conc., concentration.

tion of colony formation (Fig. 1B) and morphological changes (Fig. 1C). These results are in agreement with those of previous studies using diverse malignant cell types and various combinations of HDACIs and PIs $(15,22)$.

Normal cell function is dependent on the proper maintenance of chromatin structure. The regulation of chromatin structure is controlled by histone modifications that directly influence chromatin architecture and genome function.
Specifically, the HDAC families of proteins modulate chromatin compaction and are commonly deregulated in many tumors, including colorectal cancer (23). HDACIs interfere with tumorigenic HDAC activity; however, the precise mechanisms involved in this process remain to be elucidated (23). The anti-proliferative effects of VPA on human colorectal cancer cells may be based on the direct inhibition of HDACs by a direct influence on enzymes that are responsible for acetyla- 
A SW1116, chemosensitization with VPA/PR-39
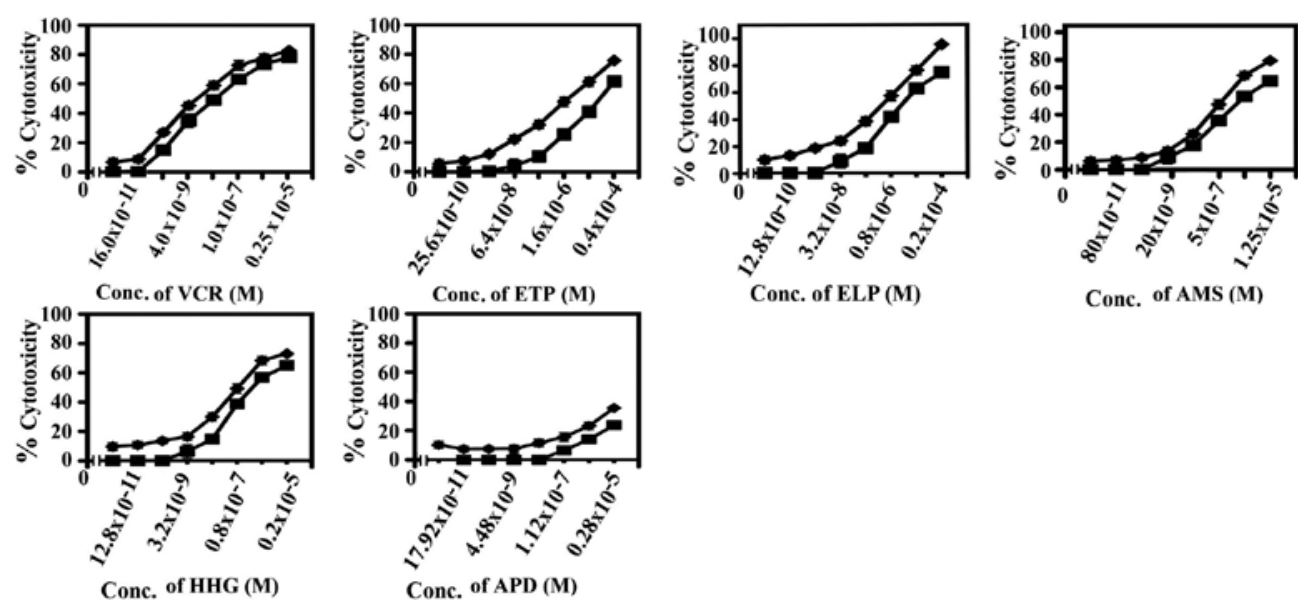

Conc. of AMS (M)

B SW 837 chemosensitization with VPA/ MG132
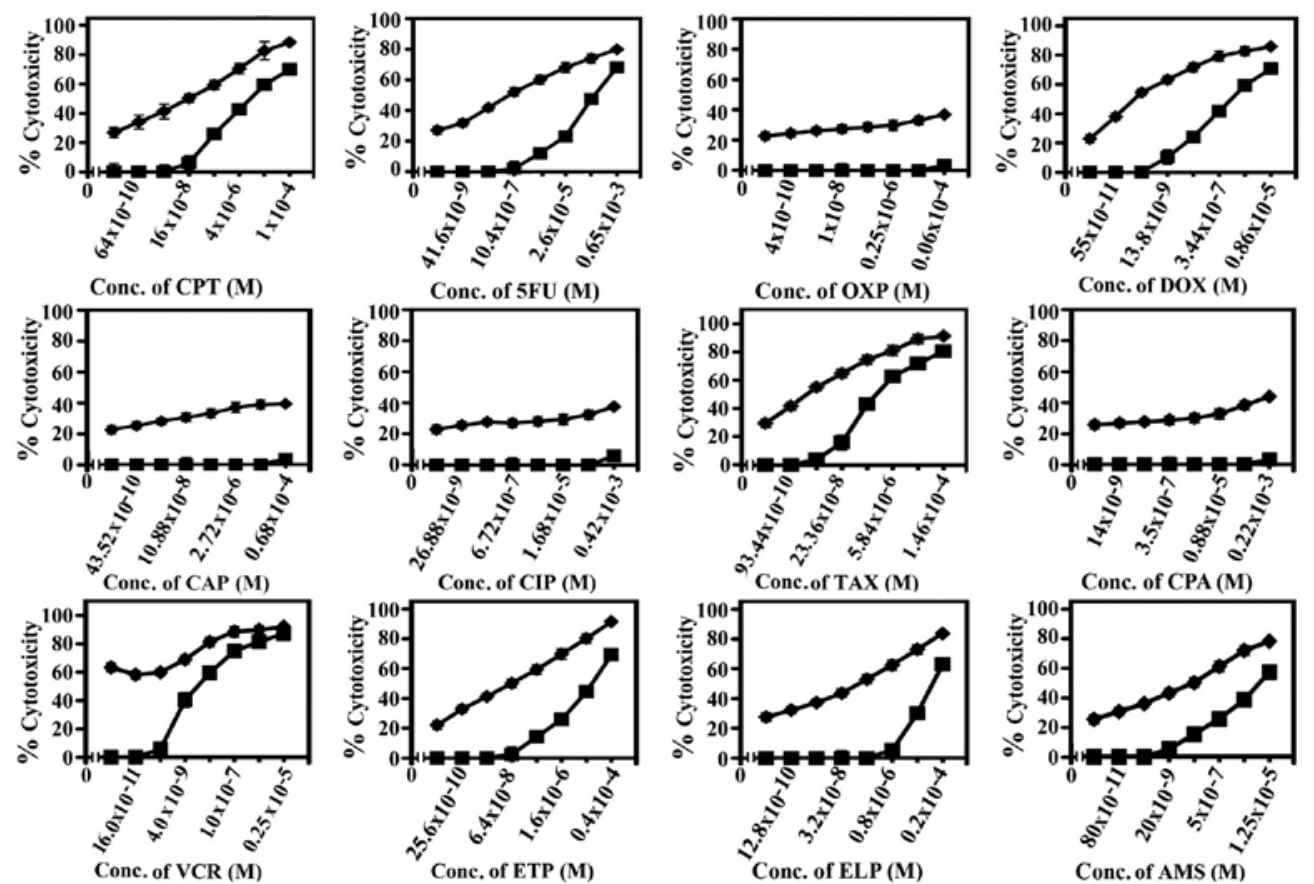

A

Conc. of VCR (M)

Conc. of ELP (M)

Conc. of AMS (M)

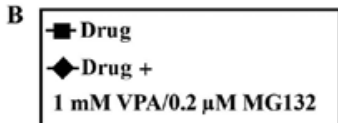

Figure 8. Chemosensitizing effect of combined treatment with valproic acid (VPA) and PR-39 and MG132 on SW1116 and SW837 colorectal cancer cells. Cells were inoculated $\left(27 \times 10^{3}\right.$ cells/well) into 96 -well plates for $18 \mathrm{~h}$. The cells were treated with various concentrations of (A) vincristine (VCR), etoposide (ETP), ellipticine (ELP), amsacrine (AMS), homoharringtonine (HHG) and aphidicolin (APD) or (B) camptothecin (CPT), 5-fluorouracil (5FU), oxaliplatin (OXP), doxorubicin (DOX), carboplatin (CAP), cisplatin (CIP), taxol (TAX), cyclophosphamide (CPA), VCR, ETP, ELP and AMS for $24 \mathrm{~h}$. The drugs were then removed, cells washed with HBSS and treated with a combination of (A) VPA (1.0 mM)/PR-39 (212 pM) or (B) VPA (1.0 mM)/MG132 (0.2 $\mu$ M) for $72 \mathrm{~h}$. Cell proliferation was monitored by MTT assay. conc., concentration.

tion and deacetylation of nucleosomal histones. In the present study, the intracellular deacetylase activity was significantly reduced $(\mathrm{P} \leq 0.0001)$ following treatment with VPA (Fig. 2A). These results are consistent with those reported in other malignant cell types $(21,24)$. By contrast, other investigators have found that intracellular deacetylase activity was inhibited in non-small cell lung cancer cell lines, which were resistant to HDACI-mediated cell death (25).

The proteasome is a fundamental non-lysosomal tool that cells use to process or degrade a variety of short-lived proteins.
Proteolysis mediated by the ubiquitin-proteasome system has been implicated in the regulation of apoptosis (26). The proteasome pathway functions upstream of mitochondrial alterations and caspase activation, and is involved in different systems, including NF- $\kappa \mathrm{B}, \mathrm{Bax}$ and Bcl-2 (27). PIs, employed alone or in combination with other anticancer agents, have been suggested as a new class of potential anticancer agents (28). This increasing interest stems not only from their direct apoptosis-inducing activity, but also from the possibility of the sensitization of neoplastic cells to other antitumor agents. 
A SW 837, chemosensitization with VPA/MG132
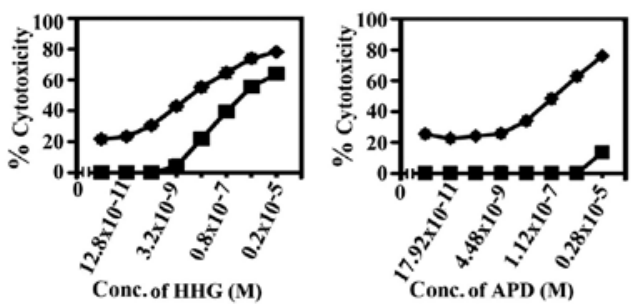

B SW 837, chemosensitization with VPA/PI-1
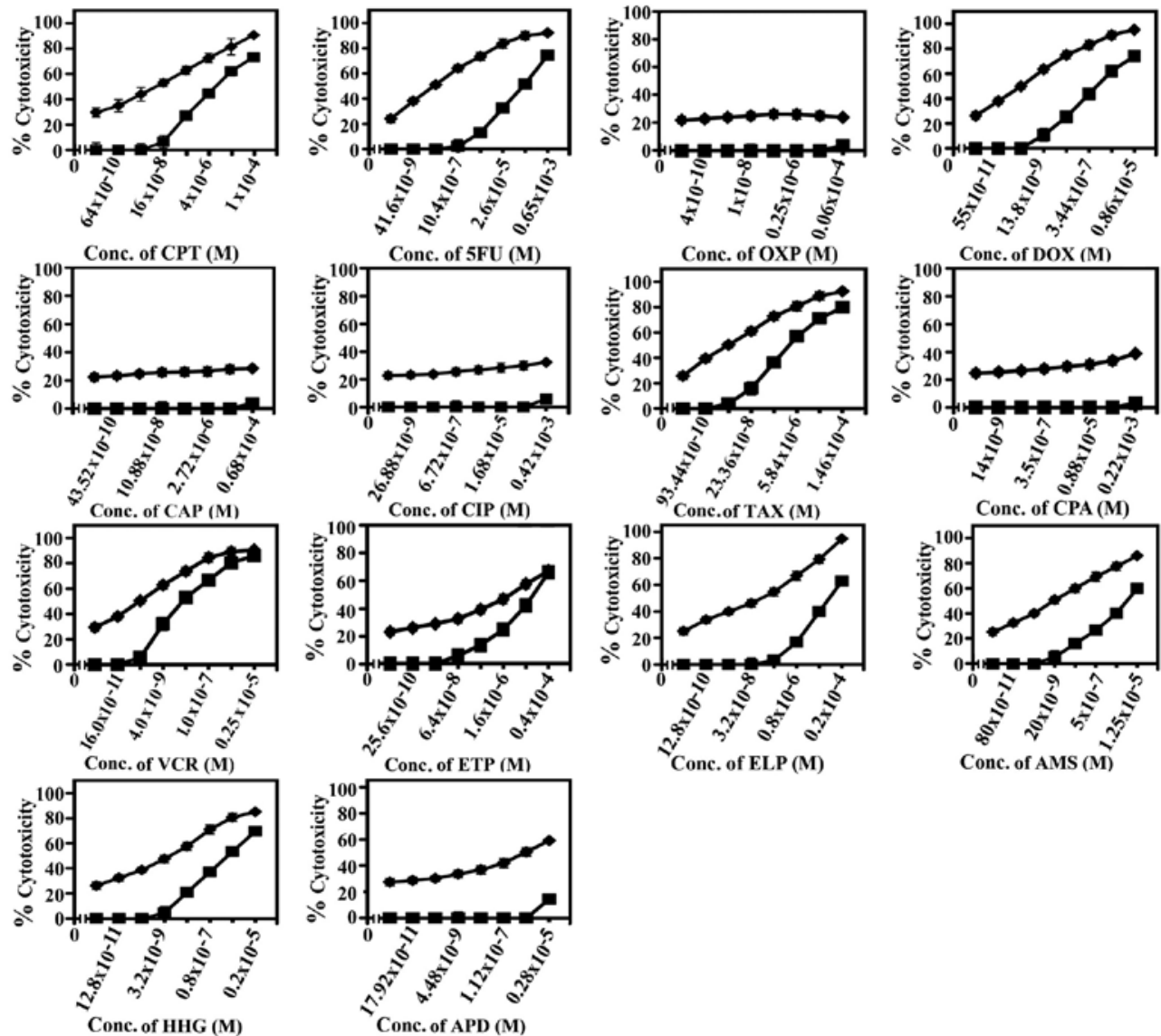

Conc. of AMS (M)
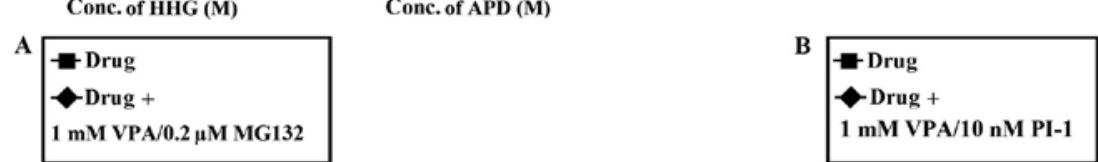

Figure 9. Chemosensitizing effect of combined treatment with valproic acid (VPA) and MG132 or VPA and proteasome inhibitor-1 (PI-1) on SW837 colorectal cancer cells. SW837 cells were seeded (27x103 cells/well) into 96-well plates for $18 \mathrm{~h}$. The cells were treated with various concentrations of (A) homoharringtonine (HHG) and aphidicolin (APD) or (B) camptothecin (CPT), 5-fluorouracil (5FU), oxaliplatin (OXP), doxorubicin (DOX), carboplatin (CAP), cisplatin (CIP), taxol (TAX), cyclophosphamide (CPA), vincristine (VCR), etoposide (ETP), ellipticine (ELP), amsacrine (AMS), homoharringtonine (HHG) and APD for $24 \mathrm{~h}$. The drugs were then removed, cells washed with HBSS and treated with a combination of (A) VPA (1.0 mM)/MG132 (0.2 $\mu$ M) or VPA (1.0 mM)/PI-1 (10 nM) for $72 \mathrm{~h}$. Cell proliferation was monitored by MTT assay. conc., concentration.

In vitro data support the idea that PIs increase the sensitivity of tumor cells to the apoptotic action of tumor necrosis factor, radiotherapy, or chemotherapy (29). In the present study, the proteasomal activity of human colorectal cancer cells was significantly decreased following exposure to the PIs, MG132 $(\mathrm{P} \leq 0.001)$, PI-1 ( $\mathrm{P} \leq 0.001)$ or PR-39 ( $\mathrm{P} \leq 0.0001)$ (Fig. B). Our results are in line with those reported by other studies using a number of different cell lines $(30,31)$.

VPA and other class I/II HDACIs, i.e., suberoylanilide hydroxamic acid (SAHA), MS-275 and sodium butyrate, have been reported to elevate the cellular levels of ROS $(32,33)$.
Although ROS induce toxicity to cells at high levels, at physiological levels, they function as part of normal cell signaling. Since the induction of cell death resulting from proteasome inhibition is linked to increased levels of ROS in leukemia cells (34), in this study, experiments were carried out to measure the capacity of proteasomal inhibition to modulate intracellular ROS content and the lethality of combined treatments with VPA and the PIs, MG132, PI-1 or PR-39, in human colorectal cancer cells. Combined treatment with VPA/MG132, VPA/PI-1 and VPA/PR-39 induced a significant $(\mathrm{P} \leq 0.0001)$ increase in ROS levels compared to the untreated cells and cells treated 
A SW 837, chemosenitization with VPA/PR-39
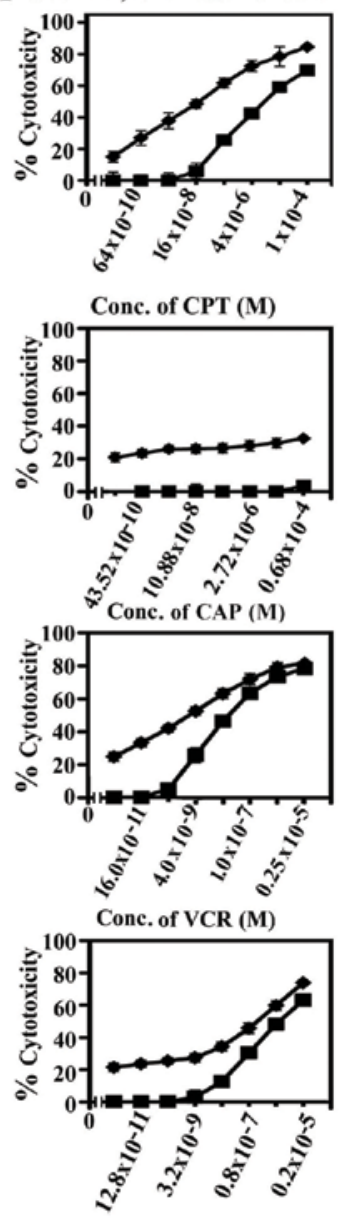

Conc. of HHG (M)
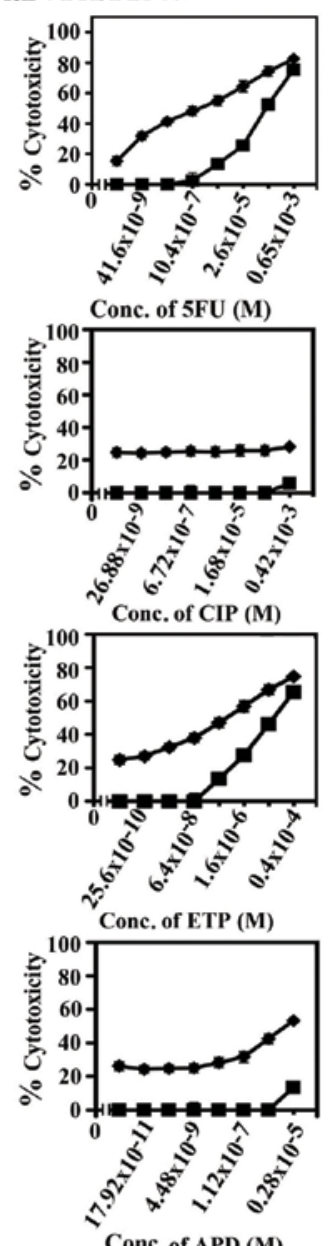

Conc. of APD (M)
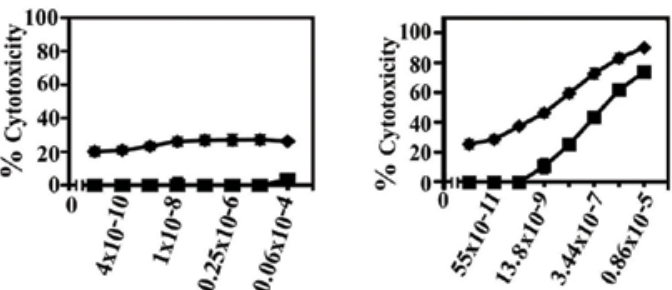

Conc. of OXP (M)
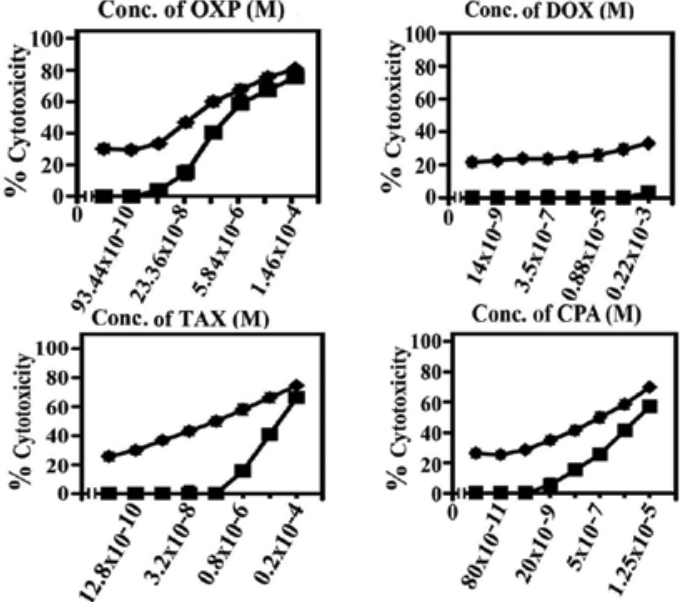

Conc. of ELP (M)

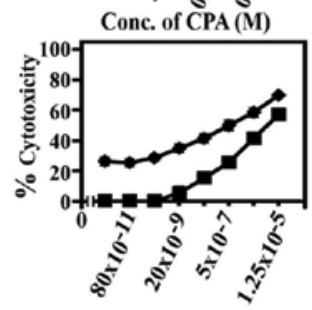

Conc. of AMS (M)

B Effect of the combination of VPA/MG132, PI-1 or PR-39 on normal human fibroblast cells CRL1554

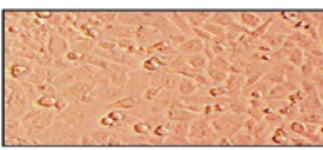

(a) UT

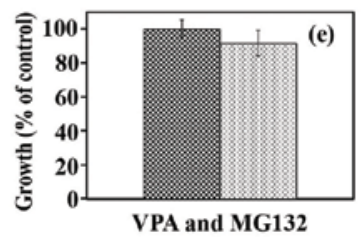

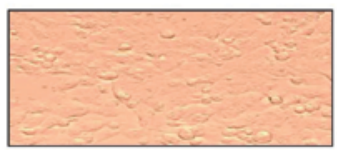

(b) VPA+MG132

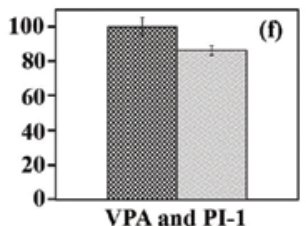

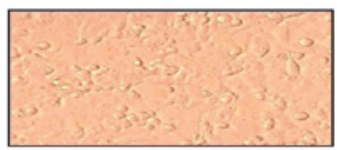

(c) $\mathrm{VPA}+\mathrm{PI}-1$

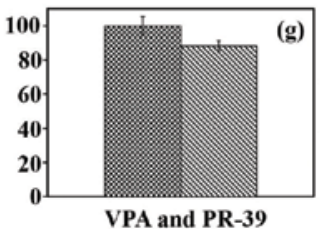

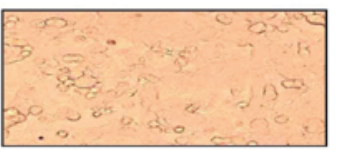

(d) VPA+PR-39

Figure 10. Chemosensitizing effect of combined treatment with valproic acid (VPA) and PR-39 on SW837 colorectal cancer cells, and the effect of the combined treatment of VPA with proteasome inhibitors (PIs) on normal human fibroblasts. (A) SW837 cells were plated (27x10 ${ }^{3}$ cells/well) into 96-well plates and allowed to grow for $18 \mathrm{~h}$. The cells were treated with various concentrations of camptothecin (CPT), 5-fluorouracil (5FU), oxaliplatin (OXP), doxorubicin (DOX), carboplatin (CAP), cisplatin (CIP), taxol (TAX), cyclophosphamide (CPA), vincristine (VCR), etoposide (ETP), ellipticine (ELP), amsacrine (AMS), homoharringtonine (HHG) and aphidicolin (APD) for $24 \mathrm{~h}$. The drugs were then removed, cells washed with HBSS and treated with a combination of VPA $(1.0 \mathrm{mM}) / / \mathrm{PR}-39(212 \mathrm{pM})$ for $72 \mathrm{~h}$. Cell proliferation was monitored by MTT assay. (B) The effect of the combined treatment with VPA (1 mM)/MG-132 $(0.2 \mu \mathrm{M})$, VPA $(1 \mathrm{mM}) / \mathrm{PI}-1(10 \mathrm{nM})$ and VPA $(1 \mathrm{mM}) / \mathrm{PR}-39(212 \mathrm{pM})$ on normal human fibroblasts (CRL1554). Control cells were treated with vehicle (DMSO at a final concentration of $0.2 \%$ ). Cell growth was monitored by MTT assay. UT, untreated cells; conc., concentration.

with VPA or one of the PIs alone (Fig. 2C). Co-administration of the antioxidant, L-NAC, $(15 \mathrm{mM})$ substantially blocked the VPA/PI-mediated increase in ROS levels (data not shown). Our results are consistent with those of other studies using different combinations of HDACs and PIs in various cell systems $(15,35)$. HDACIs have been shown to raise intracellular ROS levels (36), and our results indicated that the combination of VPA and PIs induced a greater increase in ROS levels than that observed with either agent alone. Thus, it is conceivable that this greater oxidative challenge may contribute to the synergistic effects. Importantly, the blockade of ROS using the scavenger, L-NAC, substantially reduced cell death, suggesting that ROS genera- 
Table I. $\mathrm{IC}_{50}$ and sensitization ratios of cytotoxic drugs and their combinations with the HDACI, VPA, and proteasome inhibitors in the human colorectal cancer cell line, SW1116.

SW1116

Combined treatment with the HDACI, VPA, and proteasome inhibitors

\begin{tabular}{|c|c|c|}
\hline \multicolumn{3}{|c|}{ SW1116 } \\
\hline $\mathrm{IC}_{50}(\mathrm{M})^{\mathrm{a}}$ & $\begin{array}{l}\text { Sensitization } \\
\text { ratio }^{\mathrm{b}}\end{array}$ & P-value \\
\hline $104.4 \times 10^{-9}$ & 28.6 & 0.003 \\
\hline $19.4 \times 10^{-6}$ & 41.2 & 0.001 \\
\hline $14 \times 10^{-9}$ & 14.1 & 0.013 \\
\hline $23.4 \times 10^{-8}$ & 15.6 & 0.007 \\
\hline $0.8 \times 10^{-9}$ & 18.7 & 0.028 \\
\hline $0.7 \times 10^{-7}$ & 140 & 0.0001 \\
\hline $0.16 \times 10^{-6}$ & 12.5 & 0.002 \\
\hline $0.625 \times 10^{-7}$ & 31.2 & 0.0001 \\
\hline $11.25 \times 10^{-9}$ & 17.8 & 0.001 \\
\hline $29 \times 10^{-9}$ & 138 & 0.001 \\
\hline $52.5 \times 10^{-8}$ & 185 & 0.0001 \\
\hline $51.7 \times 10^{-10}$ & 41.6 & 0.05 \\
\hline $29.25 \times 10^{-8}$ & 14.9 & 0.004 \\
\hline $5.7 \times 10^{-10}$ & 20 & 0.002 \\
\hline $0.84 \times 10^{-7}$ & 170 & 0.0001 \\
\hline $0.6 \times 10^{-6}$ & 4.2 & 0.002 \\
\hline $0.25 \times 10^{-6}$ & 8.8 & 0.0001 \\
\hline $3.75 \times 10^{-9}$ & 53.3 & 0.0001 \\
\hline $43.75 \times 10^{-8}$ & 6.8 & 0.366 \\
\hline $22.7 \times 10^{-6}$ & 3.58 & 0.224 \\
\hline $42.84 \times 10^{-9}$ & 4 & 0.288 \\
\hline $73.12 \times 10^{-8}$ & 5 & 0.327 \\
\hline $0.4 \times 10^{-8}$ & 3.75 & 0.393 \\
\hline $1.48 \times 10^{-6}$ & 6.7 & 0.12 \\
\hline $0.5 \times 10^{-6}$ & 3 & 0.122 \\
\hline $0.05 \times 10^{-5}$ & 3.9 & 0.228 \\
\hline $6 \times 10^{-8}$ & 2.5 & 0.18 \\
\hline
\end{tabular}

CPT $\left(64 \times 10^{-10}-1 \times 10^{-4} \mathrm{M}\right)+\mathrm{VPA}(1 \mathrm{mM}) / \mathrm{MG} 132(2 \mu \mathrm{M})$

$5 \mathrm{FU}\left(41.6 \times 10^{-9}-0.65 \times 10^{-3} \mathrm{M}\right)+\mathrm{VPA}(1 \mathrm{mM}) / \mathrm{MG} 132(2 \mu \mathrm{M})$

$\operatorname{DOX}\left(55 \times 10^{-11}-0.86 \times 10^{-5} \mathrm{M}\right)+\mathrm{VPA}(1 \mathrm{mM}) / \mathrm{MG} 132(2 \mu \mathrm{M})$

$\operatorname{TAX}\left(93.44 \times 10^{-10}-1.46 \times 10^{-4} \mathrm{M}\right)+\mathrm{VPA}(1 \mathrm{mM}) / \mathrm{MG} 132(2 \mu \mathrm{M})$

$\operatorname{VCR}\left(16.0 \times 10^{-11}-0.25 \times 10^{-5} \mathrm{M}\right)+\mathrm{VPA}(1 \mathrm{mM}) / \mathrm{MG} 132(2 \mu \mathrm{M})$

$\operatorname{ETP}\left(25.6 \times 10^{-10}-0.4 \times 10^{-4} \mathrm{M}\right)+\mathrm{VPA}(1 \mathrm{mM}) / \mathrm{MG} 132(2 \mu \mathrm{M})$

$\operatorname{ELP}\left(12.8 \times 10^{-10}-0.2 \times 10^{-4} \mathrm{M}\right)+\mathrm{VPA}(1 \mathrm{mM}) / \mathrm{MG} 132(2 \mu \mathrm{M})$

AMS $\left(80 \times 10^{-11}-1.25 \times 10^{-5} \mathrm{M}\right)+\mathrm{VPA}(1 \mathrm{mM}) / \mathrm{MG} 132(2 \mu \mathrm{M})$

HHG $\left(12.8 \times 10^{-11}-0.2 \times 10^{-5} \mathrm{M}\right)+\mathrm{VPA}(1 \mathrm{mM}) / \operatorname{MG} 132(2 \mu \mathrm{M})$

CPT $\left(64 \times 10^{-10}-1 \times 10^{-4} \mathrm{M}\right)+$ VPA $(1 \mathrm{mM}) / \mathrm{PI}-1(10 \mathrm{nM})$

5 FU $\left(41.6 \times 10^{-9}-0.65 \times 10^{-3} \mathrm{M}\right)+\mathrm{VPA}(1 \mathrm{mM}) / \mathrm{PI}-1(10 \mathrm{nM})$

DOX $\left(55 \times 10^{-11}-0.86 \times 10^{-5} \mathrm{M}\right)+\mathrm{VPA}(1 \mathrm{mM}) / \mathrm{PI}-1(10 \mathrm{nM})$

TAX $\left(93.44 \times 10^{-10}-1.46 \times 10^{-4} \mathrm{M}\right)+\mathrm{VPA}(1 \mathrm{mM}) / \mathrm{PI}-1(10 \mathrm{nM})$

VCR $\left(16.0 \times 10^{-11}-0.25 \times 10^{-5} \mathrm{M}\right)+\mathrm{VPA}(1 \mathrm{mM}) / \mathrm{PI}-1(10 \mathrm{nM})$

$\operatorname{ETP}\left(25.6 \times 10^{-10}-0.4 \times 10^{-4} \mathrm{M}\right)+\mathrm{VPA}(1 \mathrm{mM}) / \mathrm{PI}-1(10 \mathrm{nM})$

$\operatorname{ELP}\left(12.8 \times 10^{-10}-0.2 \times 10^{-4} \mathrm{M}\right)+\mathrm{VPA}(1 \mathrm{mM}) / \mathrm{PI}-1(10 \mathrm{nM})$

AMS $\left(80 \times 10^{-11}-1.25 \times 10^{-5} \mathrm{M}\right)+\mathrm{VPA}(1 \mathrm{mM}) / \mathrm{PI}-1(10 \mathrm{nM})$

HHG $\left(12.8 \times 10^{-11}-0.2 \times 10^{-5} \mathrm{M}\right)+\mathrm{VPA}(1 \mathrm{mM}) / \mathrm{PI}-1(10 \mathrm{nM})$

CPT $\left(64 \times 10^{-10}-1 \times 10^{-4} \mathrm{M}\right)+\mathrm{VPA}(1 \mathrm{mM}) / \mathrm{PR}-39(212 \mathrm{pM})$

5 FU $\left(41.6 \times 10^{-9}-0.65 \times 10^{-3} \mathrm{M}\right)+\mathrm{VPA}(1 \mathrm{mM}) / \mathrm{PR}-39(212 \mathrm{pM})$

DOX $\left(55 \times 10^{-11}-0.86 \times 10^{-5} \mathrm{M}\right)+\mathrm{VPA}(1 \mathrm{mM}) / \mathrm{PR}-39(212 \mathrm{pM})$

TAX $\left(93.44 \times 10^{-10}-1.46 \times 10^{-4} \mathrm{M}\right)+\mathrm{VPA}(1 \mathrm{mM}) / \mathrm{PR}-39(212 \mathrm{pM})$

VCR $\left(16.0 \times 10^{-11}-0.25 \times 10^{-5} \mathrm{M}\right)+\mathrm{VPA}(1 \mathrm{mM}) / \mathrm{PR}-39(212 \mathrm{pM})$

ETP $\left(25.6 \times 10^{-10}-0.4 \times 10^{-4} \mathrm{M}\right)+$ VPA $(1 \mathrm{mM}) / \mathrm{PR}-39(212 \mathrm{pM})$

$\operatorname{ELP}\left(12.8 \times 10^{-10}-0.2 \times 10^{-4} \mathrm{M}\right)+\mathrm{VPA}(1 \mathrm{mM}) / \mathrm{PR}-39(212 \mathrm{pM})$

AMS $\left(80 \times 10^{-11}-1.25 \times 10^{-5} \mathrm{M}\right)+\mathrm{VPA}(1 \mathrm{mM}) / \mathrm{PR}-39(212 \mathrm{pM})$

HHG $\left(12.8 \times 10^{-11}-0.2 \times 10^{-5} \mathrm{M}\right)+\mathrm{VPA}(1 \mathrm{mM}) / \mathrm{PR}-39(212 \mathrm{pM})$

${ }^{a}$ The data are based on the mean of absorbance from 3 independent experiments. ${ }^{\text {b }} \mathrm{SR}$, sensitization ratio: $\mathrm{IC}_{50}$ of drug/IC $\mathrm{C}_{50}$ of the drug + combination of valproic acid (VPA) and proteasome inhibitors. ${ }^{\circ} \mathrm{P}$-value of the combined treatment with standard chemotherapeutic drugs and the combination of VPA and PIs vs. the chemotherapeutic drug alone. HDACI, histone deacetylase inhibitor; CPT, camptothecin; 5FU, 5-fluorouracil; DOX, doxorubicin; TAX, taxol; VCR, vincristine; ETP, etoposide; ELP, ellipticine; AMS, amsacrine; HHG, homoharringtonine; PI-1, proteasome inhibitor-1.

tion plays a major role in the cytotoxicity of combined VPA and PI treatment.

Cancer cells produce higher levels of ROS than normal cells due to the increased metabolic stress and proliferative capacity. Thus, cancer cells may be more sensitive to oxidative stress as a result of high endogenous ROS levels, and this may provide a selective mechanism to induce cell death (37).

Flow cytometric analysis indicated that in human colorectal cancer cells, combined treatment with VPA/MG132, VPA/PI-1 and VPA/PR-39 induced an arrest of the cell cycle at the $S$ phase. Our results are in agreement with those reported in another study using the melanoma cell line, SK-Mel-37: the combination of VPA and hydroxyurea (HU) increased the number of cells in the $\mathrm{S}$ phase (38). The results from flow cytometry reported in that study are contradictory to those reported by other groups using several different cell systems and various combinations of HDACIs and PIs $(35,39)$.

Cell proliferation and cell death induction are two major targets in cancer therapy. There are two fundamental types of cell death, apoptosis and necrosis, which can be defined by morphological and biochemical criteria. Over the past several years, the idea that cells can commit suicide by mechanisms other than apoptosis has gained momentum (40). Apoptosis is marked by cellular shrinking, condensation of chromatin and the loss of plasma membrane integrity, resulting in the breaking up of the cell into apoptotic bodies. Whereas apoptosis is an inherent, programmed cellular death mechanism, its conceptual counterpart, necrosis, is a more uncontrolled form 
Table II. $\mathrm{IC}_{50}$ and sensitization ratios of cytotoxic drugs and their combinations with the HDACI, VPA, and proteasome inhibitors in the human colorectal cancer cell line, SW837.

SW837

Combined treatment with the HDACI, VPA, and proteasome inhibitors

\begin{tabular}{|c|c|c|c|}
\hline \multirow[b]{2}{*}{$\begin{array}{l}\text { Combined treatment with the HDACI, VPA, } \\
\text { and proteasome inhibitors }\end{array}$} & \\
\hline & $\mathrm{IC}_{50}(\mathrm{M})^{\mathrm{a}}$ & $\begin{array}{l}\text { Sensitization } \\
\text { ratio }^{\mathrm{b}}\end{array}$ & P-value \\
\hline $\mathrm{CPT}\left(64 \times 10^{-10}-1 \times 10^{-4} \mathrm{M}\right)+\mathrm{VPA}(1 \mathrm{mM}) / \mathrm{MG} 132(2 \mu \mathrm{M})$ & $108 \times 10^{-9}$ & 46.3 & 0.0001 \\
\hline $5 \mathrm{FU}\left(41.6 \times 10^{-9}-0.65 \times 10^{-3} \mathrm{M}\right)+\mathrm{VPA}(1 \mathrm{mM}) / \mathrm{MG} 132(2 \mu \mathrm{M})$ & $39.48 \times 10^{-8}$ & $3.3 \times 1020$ & 0.0001 \\
\hline $\operatorname{DOX}\left(55 \times 10^{-11}-0.86 \times 10^{-5} \mathrm{M}\right)+\mathrm{VPA}(1 \mathrm{mM}) / \mathrm{MG} 132(2 \mu \mathrm{M})$ & $171.8 \times 10^{-11}$ & $3.76 \times 102$ & 0.0001 \\
\hline $\operatorname{TAX}\left(93.4 \times 10^{-10}-1.46 \times 10^{-4} \mathrm{M}\right)+\mathrm{VPA}(1 \mathrm{mM}) / \mathrm{MG} 132(2 \mu \mathrm{M})$ & $292.5 \times 10^{-10}$ & 75.2 & 0.0001 \\
\hline $\operatorname{VCR}\left(16 \times 10^{-11}-0.25 \times 10^{-5} \mathrm{M}\right)+\mathrm{VPA}(1 \mathrm{mM}) / \mathrm{MG} 132(2 \mu \mathrm{M})$ & $0.5 \times 10^{-8}$ & 15 & 0.0001 \\
\hline $\operatorname{ETP}\left(25.6 \times 10^{-10}-0.4 \times 10^{-4} \mathrm{M}\right)+\mathrm{VPA}(1 \mathrm{mM}) / \mathrm{MG} 132(2 \mu \mathrm{M})$ & $5.25 \times 10^{-8}$ & $1.88 \times 102$ & 0.0001 \\
\hline $\operatorname{ELP}\left(12.8 \times 10^{-10}-0.2 \times 10^{-4} \mathrm{M}\right)+\mathrm{VPA}(1 \mathrm{mM}) / \mathrm{MG} 132(2 \mu \mathrm{M})$ & $0.8 \times 10^{-5}$ & 1.25 & 0.0001 \\
\hline $\operatorname{AMS}\left(80 \times 10^{-11}-1.25 \times 10^{-5} \mathrm{M}\right)+\mathrm{VPA}(1 \mathrm{mM}) / \mathrm{MG} 132(2 \mu \mathrm{M})$ & $0.625 \times 10^{-5}$ & 104 & 0.0001 \\
\hline HHG $\left(12.8 \times 10^{-11}-0.2 \times 10^{-5} \mathrm{M}\right)+\mathrm{VPA}(1 \mathrm{mM}) / \mathrm{MG} 132(2 \mu \mathrm{M})$ & $3.75 \times 10^{-8}$ & 40 & 0.0001 \\
\hline $\mathrm{CPT}\left(64 \times 10^{-10}-1 \times 10^{-4} \mathrm{M}\right)+\mathrm{VPA}(1 \mathrm{mM}) / \mathrm{PI}-1(10 \mathrm{nM})$ & $104.4 \times 10^{-9}$ & 95.7 & 0.0001 \\
\hline $5 \mathrm{FU}\left(41.6 \times 10^{-9}-0.65 \times 10^{-3} \mathrm{M}\right)+\mathrm{VPA}(1 \mathrm{mM}) / \mathrm{PI}-1(10 \mathrm{nM})$ & $21 \times 10^{-8}$ & $6.2 \times 102$ & 0.0001 \\
\hline $\operatorname{DOX}\left(55 \times 10^{-11}-0.86 \times 10^{-5} \mathrm{M}\right)+\mathrm{VPA}(1 \mathrm{mM}) / \mathrm{PI}-1(10 \mathrm{nM})$ & $27.5 \times 10^{-10}$ & $3.12 \times 102$ & 0.0001 \\
\hline TAX $\left(93.44 \times 10^{-10}-1.46 \times 10^{-4} \mathrm{M}\right)+\mathrm{VPA}(1 \mathrm{mM}) / \mathrm{PI}-1(10 \mathrm{nM})$ & $46.8 \times 10^{-9}$ & $1.09 \times 102$ & 0.0001 \\
\hline $\operatorname{VCR}\left(16.0 \times 10^{-11}-0.25 \times 10^{-5} \mathrm{M}\right)+\mathrm{VPA}(1 \mathrm{mM}) / \mathrm{PI}-1(10 \mathrm{nM})$ & $0.8 \times 10^{-9}$ & 21.8 & 0.01 \\
\hline $\operatorname{ETP}\left(25.6 \times 10^{-10}-0.4 \times 10^{-4} \mathrm{M}\right)+$ VPA $(1 \mathrm{mM}) / \mathrm{PI}-1(10 \mathrm{nM})$ & $0.17 \times 10^{-5}$ & 5.8 & 0.002 \\
\hline $\operatorname{ELP}\left(12.8 \times 10^{-10}-0.2 \times 10^{-4} \mathrm{M}\right)+\mathrm{VPA}(1 \mathrm{mM}) / \mathrm{PI}-1(10 \mathrm{nM})$ & $0.4 \times 10^{-7}$ & 187 & 0.0001 \\
\hline $\operatorname{AMS}\left(80 \times 10^{-11}-1.25 \times 10^{-5} \mathrm{M}\right)+\mathrm{VPA}(1 \mathrm{mM}) / \mathrm{PI}-1(10 \mathrm{nM})$ & $0.2 \times 10^{-7}$ & 405 & 0.0001 \\
\hline HHG $\left(12.8 \times 10^{-11}-0.2 \times 10^{-5} \mathrm{M}\right)+\mathrm{VPA}(1 \mathrm{mM}) / \mathrm{PI}-1(10 \mathrm{nM})$ & $3.75 \times 10^{-9}$ & 93.3 & 0.0001 \\
\hline $\mathrm{CPT}\left(64 \times 10^{-10}-1 \times 10^{-4} \mathrm{M}\right)+\mathrm{VPA}(1 \mathrm{mM}) / \mathrm{PR}-39(212 \mathrm{pM})$ & $14 \times 10^{-8}$ & 53.7 & 0.001 \\
\hline $5 \mathrm{FU}\left(41.6 \times 10^{-9}-0.65 \times 10^{-3} \mathrm{M}\right)+\mathrm{VPA}(1 \mathrm{mM}) / \mathrm{PR}-39(212 \mathrm{pM})$ & $32.8 \times 10^{-7}$ & 39.6 & 0.0001 \\
\hline $\operatorname{DOX}\left(55 \times 10^{-11}-0.86 \times 10^{-5} \mathrm{M}\right)+\mathrm{VPA}(1 \mathrm{mM}) / \mathrm{PR}-39(212 \mathrm{pM})$ & $17.1 \times 10^{-9}$ & 37.8 & 0.001 \\
\hline $\operatorname{TAX}\left(93.44 \times 10^{-10}-1.46 \times 10^{-4} \mathrm{M}\right)+\mathrm{VPA}(1 \mathrm{mM}) / \mathrm{PR}-39(212 \mathrm{pM})$ & $23.4 \times 10^{-8}$ & 9.4 & 0.0001 \\
\hline $\operatorname{VCR}\left(16.0 \times 10^{-11}-0.25 \times 10^{-5} \mathrm{M}\right)+\mathrm{VPA}(1 \mathrm{mM}) / \mathrm{PR}-39(212 \mathrm{pM})$ & $1.5 \times 10^{-9}$ & 13.3 & 0.041 \\
\hline $\operatorname{ETP}\left(25.6 \times 10^{-10}-0.4 \times 10^{-4} \mathrm{M}\right)+\mathrm{VPA}(1 \mathrm{mM}) / \mathrm{PR}-39(212 \mathrm{pM})$ & $2.52 \times 10^{-6}$ & 35.7 & 0.0001 \\
\hline $\operatorname{ELP}\left(12.8 \times 10^{-10}-0.2 \times 10^{-4} \mathrm{M}\right)+\mathrm{VPA}(1 \mathrm{mM}) / \mathrm{PR}-39(212 \mathrm{pM})$ & $0.16 \times 10^{-6}$ & 46.8 & 0.0001 \\
\hline AMS $\left(80 \times 10^{-11}-1.25 \times 10^{-5} \mathrm{M}\right)+\mathrm{VPA}(1 \mathrm{mM}) / \mathrm{PR}-39(212 \mathrm{pM})$ & $0.05 \times 10^{-5}$ & 16 & 0.0001 \\
\hline HHG $\left(12.8 \times 10^{-11}-0.2 \times 10^{-5} \mathrm{M}\right)+\mathrm{VPA}(1 \mathrm{mM}) / \mathrm{PR}-39(212 \mathrm{pM})$ & $0.8 \times 10^{-7}$ & 5 & 0.013 \\
\hline
\end{tabular}

${ }^{\mathrm{a}}$ The data are based on the mean of absorbance from 3 independent experiments. ${ }^{\mathrm{b}} \mathrm{SR}$, sensitization ratio $=\mathrm{IC}_{50}$ of drug/IC $\mathrm{C}_{50}$ of the drug + combination of VPA and proteasome inhibitors. ${ }^{\mathrm{P}} \mathrm{P}$-value of the combined treatment with standard chemotherapeutic drugs and the combination of valproic acid (VPA) and PIs vs. the chemotherapeutic drug alone. HDACI, histone deacetylase inhibitor; CPT, camptothecin; 5FU, 5-fluorouracil; DOX, doxorubicin; TAX, taxol; VCR, vincristine; ETP, etoposide; ELP, ellipticine; AMS, amsacrine; HHG, homoharringtonine; PI-1, proteasome inhibitor-1.

of death and is characterized by cellular swelling and disruption of the plasma membrane, leading to the release of the cellular components and inflammatory tissue response (41).

HDACIs are known to induce programmed cell death in cancer cells, although the underlying mechanisms are far from being understood and seem to be very heterogeneous. Many HDACI-mediated death mechanisms have already been described, including the induction of a senescence-like phenotype (42) and autophagic cell death (43). This diversity of cell death mechanisms has also been observed for VPA (44). In the present study, the co-administration of VPA with PI, MG132, PI-1 or PR-39 induced a marked increase in apoptosis in human colorectal cancer cells. Our results are consistent with those reported by other groups using several different cell systems and various combinations of HDACIs and PIs $(1,15,22,35,39)$.

Mitochondria play a decisive role in apoptosis (45), functioning as integrators of different pro-apoptotic signaling pathways. In response to these signals, mitochondria activate megachannels (also known as permeability transition pores) that are present between the inner and outer mitochondrial membrane. Bcl-2, a fundamental death antagonist protein, inhibits megachannel opening, whereas, Bax a death agonist protein, facilitates the opening of megachannels (46). The increase in the content of agonists and the concomitant decrease in the content of antagonists stimulate the release of cytochrome $c$ from the mitochondria, with the consequent activation of caspases. In this study, we examined whether VPA, 
PI-1 and their combination are capable of inducing changes in the levels of Bax and cytochrome $c$ in both the mitochondria and cytosol. Our results indicated that after $24 \mathrm{~h}$ of co-exposure to VPA and PI-1, cytochrome $c$ was released from the mitochondria. Such an event may be responsible for the production of the apoptosome, with the consequent activation of caspase-9, which in turn activates caspase-3 (45). Our results support the hypothesis that the release of cytochrome $c$ is induced in VPA/ PI-1-treated colorectal cancer cells by the decrease in the level of the anti-apoptotic factor, Bcl-2, and the concomitant increase in the level of the pro-apoptotic factor, Bax.

The NF- $\kappa$ B pathway is one of the most important signaling cascades that suppresses apoptosis, enhances chemoresistance and promotes tumorigenesis by increasing the expression of cellular survival signals (47). Bortezomib prevents $\mathrm{NF}-\kappa \mathrm{B}$ nuclear translocation and subsequent transactivation, which may lower the threshold for HDACI lethality (48). Bortezomib has been shown to sensitize B-lymphoma cells to HDACImediated apoptosis through the inhibition of the NF- $\kappa \mathrm{B}$ pathway (31). In the present study, we examined the change in NF- $\mathrm{NB}$ distribution in the human SW837 colorectal cancer cell line to determine whether NFKB is involved in the synergistic apoptotic effects of combined treatment with VPA and PI-1. Our results demonstrated an elevated level of NF- $\kappa \mathrm{B}$ in the cytoplasm of colorectal cancer cells, and a concomitant marked decrease in the amount of nuclear NF- $\kappa \mathrm{B}$ following co-treatment with VPA and PI-1. These results are in line with those reported by others $(1,25,31)$. Our results demonstrated that co-treatment with VPA/PI-1 affects the nuclear translocation of NF- $\kappa \mathrm{B}$ in colorectal cancer cells, suggesting that the dysfunction of $N F-\kappa B$ may be involved in the synergistic apoptotic effects of VPA and PIs.

It has been reported that HDACIs suppress NF- $\kappa \mathrm{B}$ in part by suppressing the cellular proteasome activity. In a study using colon cancer cells, Place et al (49) found that HDACI reduced cellular proteasome activity by reducing the expression of the catalytic $\beta$-type subunits of the proteasome. HDAC inhibition was found to specifically downregulate the expression of the three catalytic $\beta$-subunits, $\beta 5, \beta 1$ and $\beta 2$, which are responsible for all the endopeptidase activities associated with the proteasome. The reduced levels in these catalytic subunits results in the intracellular suppression of proteasome activity (49). By downregulating proteasome activity, HDACIs stabilize I $\mathrm{B} \alpha$. Under normal conditions, I $\mathrm{B} \alpha$ is phosphorylated, ubiquitinated and degraded by the proteasome, releasing NF- $\mathrm{BB}$.

Multiple potential molecular mechanisms may contribute to the synergy between VPA and MG132, PI-1 or PR-39, and add to the effects of proteasome and HDAC inhibition. Cytoprotective pathways, such as NF- $\mathrm{B}, \mathrm{ERK}$ and AKT, confer a survival advantage on colorectal cancer cells, not only by protecting the cells from apoptosis, but also by rendering them resistant to conventional cytotoxic drugs.

Interruption of the Raf-1/MEK/ERK pathway precedes pro-apoptotic signaling (50). Specific blockade of this pathway by bortezomib synergistically potentiates the HDCI-induced apoptosis of myeloid leukemia cells (51). In the present study, combined treatment with PI, PI-1 and HDACI, VPA markedly downregulated the levels of the phosphorylated form of ERK. These findings further establish the functional complementation of both agents in the inhibition of the ERK pathway. Our results are in line with those reported by others (52). Our results also demonstrated that the co-administration of VPA and PI-1 markedly attenuated the levels of the phosphorylated form of AKT, indicating an additional role in AKT signaling, which is to further down-modulate the apoptotic threshold. Cross-talk between the ERK and AKT cascades has been described (53) and thus, in human colorectal cancer cells, the combined downregulation of ERK and AKT may be considerably more lethal than the interruption of either pathway alone. Our results are in agreement with those reported by other groups using different cell lines and various combinations of HDACIs and PIs $(52,54)$.

Similar to ERK, JNK is also a member of the MAPK pathways and is implicated in the control of cellular survival and stress responses. However, differences do exist; ERK activation is generally associated with enhanced cell survival, whereas JNK is related to cell death. The bortezomib-mediated induction of apoptosis in leukemia cells has been linked to JNK activation (55). The upregulation of stress-related cascades is also one of the important factors involved in SAHA-mediated lethality (56). In the present study, when VPA was combined with the PI, PI-1, a marked increase in JNK expression was observed. Our results are in line with those reported in other groups using different cell line systems and various combinations of HDAC and PIs $(52,55,56)$.

The mechanisms by which HDAC and PIs exert their cytotoxic effects have not been fully delineated and are likely to be multifactorial and cell line-specific. Numerous genes are affected by PIs or VPA, and it is therefore likely that a combination of these effects may lead to the synergy observed between the two classes of agents. As cyclin-dependent kinases (CDKs) and CDKIs are critical cell regulators, we investigated whether their expression is affected by treatment with VPA/ PIs. Our results revealed that CDK1, CDK4 and CDC25A were downregulated. By contrast, p15, p19, p21 and p27 were differentially upregulated following co-treatment with VPA and PI-1. These results are in agreement with those reported in previous studies $(24,38)$.

Despite the relatively uniform synergistic induction of apoptosis by HDACIs and PIs, the molecular pathways involved in the response to the combination treatment are not yet fully understood and may vary between different malignancies $(5,52)$. The synergistic induction of apoptosis in our in vitro model of human colorectal cancer was associated with the upregulation of the expression of pro-apoptotic genes, including Bax, Bad, Bim, Apaf-1 and AIF, and caspase-3, -8 and -9 , as well with as the downregulation of the anti-apoptotic genes, including Bcl-2, XIAP and FLIP. These results are in agreement with those reported on other malignancies using various HDACIs and PIs $(24,57,58)$.

Cancer patients often develop chemoresistance, and increasing the concentration of cytotoxic drugs fails to significantly improve the therapeutic response. One hypothesis to explain the development of chemoresistance is an acquired resistance of the tumor cells to apoptosis (59), allowing tumors to withstand high levels of chemotherapy. Tumor cells that are resistant to apoptosis also exhibit an increased proliferative capacity.

Synergism has been observed when HDACIs are combined with docetaxel, epothilone $\mathrm{B}$ and gemcitabine in breast 
cancer (60), combined with 5FU in colon cancer (61), combined with etoposide, camptothecin, doxorubicin and cisplatin in glioblastoma (62), combined with topoisomerase II inhibitors, cytarabine and fludarabine in leukemia (63) and combined with cytarabine, etoposide and topotecan in non-Hodgkin's lymphoma, chronic lymphocytic leukemia (CCL) and multiple myeloma cells (64).

In this study, combined treatment with VPA and the PIs, MG132, PI-1 or PR-39, markedly decreased the apoptotic threshold of colorectal cancer cells. These results led us to examine the efficacy of the combined treatments of VPA and PIs to enhance the sensitivity of human colorectal cancer cells to conventional chemotherapeutic drugs of various modes of action. Our results demonstrated that the various combinations of VPA and MG132, PI-1 or PR-39 differentially increased the sensitivity of colorectal cancer cells to conventional chemotherapeutic agents in a VPA/PI combined- and colorectal cancer subtype-dependent manner (Figs. 6-10 and Tables I and II). These results are consistent with findings in other malignancies $(59,65,66)$

The net balance between cytoprotective pathways and stress-related cascades is known to be a critical determinant of cell death. VPA may interact with PIs by disrupting multiple cytoprotective signaling pathways and by shifting the balance toward their stress-related counterparts, which trigger mitochondrial damage, caspase activation and eventually lead to irreversible engagement of the apoptotic cascade in human colorectal cancer cells.

Clinical trials have been conducted to determine the safety, toxicity and maximum dose of VPA alone or in combination with other drugs in solid tumor malignancies and to define its clinical feasibility (67). Existing preclinical and preliminary clinical data strongly suggest that VPA is a drug with potential to eventually be used in combination therapies, either with classical cytotoxic or other molecular-targeted drugs or radiation (68). The issue of drug costs cannot be underestimated. A contemporaneous and highly discussed topic in cancer therapy is drug access for low and middle income populations (69); thus, it appears obvious that if the efficacy of VPA is confirmed in cancer therapy, it will be widely available.

The findings reported in the present study have important clinical implications. Molecular targeting of HDAC and the proteasome in combination synergistically induces apoptosis and may exert a therapeutic effect at lower concentrations of each drug, thus reducing the toxicity of the therapeutic treatment. This combination strategy provides a promising rationale for its use in the treatment of colorectal cancer and other malignancies.

\section{Acknowledgements}

This study was supported by Kuwait University, Research Grant no. SL05/11. Western blot scanning was carried out by the Research Core Facility (RCF), AbdulMohsen AbdulRazzaq Health Sciences Centre (HSC), Kuwait University (KU).

\section{References}

1. Pitts TM, Morrow M, Kaufman SA, et al: Vorinostat and bortezomib exert synergistic antiproliferative and proapoptotic effects in colon cancer cell models. Mol Cancer Ther 8: 342-349, 2009.
2. Göttlicher M, Minucci S, Zhu P, et al: Valproic acid derivatives: A novel class of HDAC inhibitors inducing differentiation of transformed cells. EMBO J 20: 6969-6978, 2001.

3. Tan J, Cang S, Ma Y, et al: Novel histone deacetylase inhibitors in clinical trials as anti-cancer agents. J Hematol Oncol 3: 5, 2010.

4. Nolan L, Johnson PWM, Ganesan A, et al: Will histone deacetylase inhibitors require combination with other agents to fulfil their therapeutic potential? Br J Cancer 99: 689-694, 2008.

5. Dai Y, Chen S, Wang L, et al: Bortezomib interacts synergistically with belinostat in human acute myeloid leukaemia and acute lymphoblastic leukaemia cells in association with perturbations in NF- $\mathrm{KB}$ and Bim. Br J Haematol 153: 222-235, 2011.

6. Adams J: The proteasome: a suitable antineoplastic target. Nat Rev Cancer 4: 349-360, 2004.

7. Orlowski RZ and Kuhn DJ: Proteasome inhibitors in cancer therapy: lessons from the first decade. Clin Cancer Res 14: 1649-1657, 2008

8. Bai J, Demirjian A, Sui J, et al: Histone deacetylase inhibitor trichostatin A and proteasome inhibitor PS-341 synergistically induce apoptosis in pancreatic cells. Biochem Biophys Res Commun 4: 1245-1253, 2006.

9. Pei XY, Dai Y and Grant S: Synergistic induction of oxidative injury and apoptosis in human multiple myeloma cells by the proteasome inhibitor bortezomib and histone deacetylase inhibitors. Clin Cancer Res 11: 3839-3852, 2004.

10. Emanuele S, Lauricella M, Carlisi D, et al: SAHA induces apoptosis in hepatoma cells and synergistically interact with proteasome inhibitor Bortezomib. Apoptosis 12: 1327-1338, 2007.

11. Abaza MS, Al-Safar A, Al-Sawan S, et al: c-myc anti-sense oligonucleotides sensitize human colorectal cancer cells to chemotherapeutic drugs. Tumour Biol 29: 287-303, 2008.

12. Abaza MSI: Augmentation of the anticancer effects of proteasome inhibitors by combination with sodium butyrate in human colorectal cancer cells. Exp Ther Med 1: 675-693, 2010.

13. Bradford MM: A rapid and sensitive method for the quantitation of microgram quantities of protein utilizing the principle of protein-dye binding. Anal Biochem 72: 248-254, 1976.

14. Kwon SH, Ahn SH, Kim YK, et al: Apicidin, a histone deacetylase inhibitor, induces apoptosis and Fas/Fas ligand expression in human acute promyelocytic leukemia cells. J Biol Chem 277: 2073-2080, 2002.

15. Premkumar DR, Jane EP, Agostino NR, et al: Bortezomibinduced sensitization of malignant human glioma cells to vorinostat-induced apoptosis depends on reactive oxygen species production, mitochondrial dysfunction, noxa upregulation, Mcl-1 cleavage, and DNA damage. Mol Carcinog 52: 118-133, 2013.

16. Murphy KM, Streips UN and Lock RB: Bcl-2 inhibits a Fas-induced conformational change in the Bax $\mathrm{N}$ terminus and Bax mitochondrial translocation. J Biol Chem 275: 17225-17228, 2000.

17. Knupfer MM, Pulzer F, Schindler I, et al: Different effects of valproic acid on proliferation and migration of malignant glioma cells in vitro. Anticancer Res 21: 347-351, 2001.

18. Barbetti V, Gozzini A, Cheloni G, et al: Time- and residuespecific differences in histone acetylation induced by VPA and SAHA in AML1/ETO-positive leukemia cells. Epigenetics 8: 210-219, 2013.

19. Sztanjnkrycer MD: Valproic acid toxicity: overview and management. J Toxicol Clin Toxicol 40: 789-801, 2002.

20. Chateauvieux S, Morceau F, Dicato M and Diederich M: Molecular and therapeutic potential and toxicity of valproic acid. J Biomed Biotechnol 2010: 479364, 2010.

21. Kostrouchová M, Kostrouch Z and Kostrouchová M: Valproic acid, a molecular lead to multiple regulatory pathways. Folia Biol (Praha) 53: 37-49, 2007.

22. Bastian L, Hof J, Pfau M, et al: Synergistic activity of bortezomib and HDACi in preclinical models of B-cell precursor acute lymphoblastic leukemia via modulation of $\mathrm{p} 53, \mathrm{PI} 3 \mathrm{~K} / \mathrm{AKT}$, and NF-кB. Clin Cancer Res 19: 1445-1457, 2013.

23. Stypula-Cyrus Y, Damania D, Kunte DP, et al: HDAC up-regulation in early colon field carcinogenesis is involved in cell tumorigenicity through regulation of chromatin structure. PLoS One 8: e64600, 2013.

24. Sidana A, Wang M, Shabbeer S, et al: Mechanism of growth inhibition of prostate cancer xenografts by valproic acid. J Biomed Biotech 2012: 180363, 2012.

25. Denlinger C, Keller M, Mayo M, et al: Combined proteasome and histone deacetylase inhibition in non-small cell lung cancer. J Thorac Cardiovasc Surg 127: 1078-1086, 2004.

26. Drexler HC, Risau W and Konerding MA: Inhibition of proteasome function induces programmed cell death in proliferating endothelial cells. FASEB J 14: 65-77, 2000. 
27. Li B and Dou QP: Bax degradation by the ubiquitin/proteasomedependent pathway: involvement in tumor survival and progression. Proc Natl Acad Sci 97: 3850-3855, 2000.

28. Adams J, Palombella VJ, Sausville EA, et al: Proteasome inhibitors: a novel class of potent and effective antitumor agents. Cancer Res 59: 2615-2622, 1999.

29. Chandra J, Niemer I, Gilbreath J, et al: Proteasome inhibitors induce apoptosis in glucocorticoid-resistant chronic lymphocytic leukemic lymphocytes. Blood 92: 4220-4229, 1998.

30. Miller CP, Ban K, Dujka ME, et al: NPI-0052, a novel proteasome inhibitor, induces caspase-8 and ROS-dependent apoptosis alone and in combination with HDAC inhibitors in leukemia cells. Blood 110: 267-277, 2007.

31. Heider U, Metzler I, Kaiser M, et al: Synergistic interaction of the histone deacetylase inhibitor SAHA with the proteasome inhibitor bortezomib in mantle cell lymphoma. Eur J Haematol 80: $133-142,2008$

32. Defoort EN, Kim PM and Winn LM: Valproic acid increases conservative homologous recombination frequency and reactive oxygen species formation: a potential mechanism for valproic acid-induced neural tube defects. Mol Pharmacol 69: 1304-1310, 2006

33. Rahmani M, Reese E, Dai Y, et al: Coadministration of histone deacetylase inhibitors and perifosine synergistically induces apoptosis in human leukemia cells through Akt and ERK1/2 inactivation and the generation of ceramide and reactive oxygen species. Cancer Res 65: 2422-2432, 2005

34. Dolado I, Swat A, Ajenjo N, et al: p38alpha MAP kinase as a sensor of reactive oxygen species in tumorigenesis. Cancer Cell 11: 191-205, 2007.

35. Dasmahapatra G, Lembersky D, Son MP, et al: Carfilzomib interact synergistically with histone deacetylase inhibitors in mantle cell lymphoma cells in vitro and in vivo. Mol Cancer Ther 10: 1686-1697, 2011

36. Ungerstedt JS, Sowa Y, Xu WS, et al: Role of thioredoxin in the response of normal and transformed cells to histone deacetylase inhibitors. Proc Natl Acad Sci USA 102: 673-678, 2005.

37. Chen Y, McMillan-Ward E, Kong J, et al: Oxidative stress induces autophagic cell death independent of apoptosis in transformed and cancer cells. Cell Death Differ 15: 171-182, 2008

38. Krämer $\mathrm{OH}$, Knauer SK, Zimmermann D, et al: Histone deacetylase inhibitors and hydroxyurea modulate the cell cycle and cooperatively induce apoptosis. Oncogene 27: 732-740, 2008

39. Nile D, Huang K, Yin S, et al: Synergistic/additive interaction of valproic acid with bortezomib on proliferation and apoptosis of acute myeloid leukemia cells. Leuk Lymphoma 53: 2487-2495, 2012.

40. Proskuryakov SY, Konoplyannikov AG and Gabai VL: Necrosis: a specific form of programmed cell death? Exp Cell Res 283 $1-16,2003$.

41. Hirsch T, Marchetti P, Susin SA, et al: The apoptosis-necrosis paradox. Apoptogenic proteases activated after mitochondrial permeability transition determine the mode of cell death Oncogene 15: 1573-1581, 1997.

42. Place RF, Noonan EJ and Giardina C: HDACs and the senescent phenotype of WI-38 cells. BMC Cell Biol 6: 37, 2005.

43. Shao Y, Gao Z, Marks PA and Jiang X: Apoptotic and autophagic cell death induced by histone deacetylase inhibitors. Proc Natl Acad Sci USA 101: 18030-18035, 2004

44. Li XN, Shu Q, Su JM, et al: Valproic acid induces growth arrest, apoptosis, and senescence in medulloblastoma by increasing histone hyperacetylation and regulating expression of $\mathrm{p} 21 \mathrm{Cip1}$ CDK4, and CMYC. Mol Cancer Ther 4: 1912-1922, 2005.

45. Green DR and Reed JC: Mitochondria and apoptosis. Science (Washington DC), 281: 1309-1312, 1998.

46. Schendel SL, Montal M and Reed JC: Bcl-2 family proteins as ion-channels. Cell Death Differ 5: 372-380, 1998.

47. Bharti AC and Aggarwal BB: Nuclear factor-kappa B and cancer: its role in prevention and therapy. Biochem Pharmacol 64: 883-888, 2002.

48. Nalepa G and Wade Harper J: Therapeutic anti-cancer targets upstream of the proteasome. Cancer Treat Rev 29 (Suppl 1) S49-S57, 2003.

49. Place RF, Noonan EJ and Giardina C: HDAC inhibition prevents NF-kappa B activation by suppressing proteasome activity: Down-regulation of proteasome subunit expression stabilizes I kappa B alpha. Biochem Pharmacol 70: 394-406, 2005.

50. Lewis TS, Shapiro PS and Ahn NG: Signal transduction through MAP kinase cascades. Adv Cancer Res 74: 49-139, 1998.
51. Nishioka C, Ikezoe T, Yang J, et al: Inhibition of MEK/ERK signaling synergistically potentiates histone deacetylase inhibitorinduced growth arrest, apoptosis and acetylation of histone $\mathrm{H} 3$ on p21waf 1 promoter in acute myelogenous leukemia cell. Leukemia 22: 1449-1452, 2008.

52. Zhang QL, Wang L, Zhang YW, et al: The proteasome inhibitor bortezomib interacts synergistically with the histone deacetylase inhibitor suberoylanilide hydroxamic acid to induce T-leukemia/ lymphoma cells apoptosis. Leukemia 23: 1507-1514, 2009.

53. Shelton JG, Blalock WL, White ER, et al: Ability of the activated PI3K/Akt oncoproteins to synergize with MEK1 and induce cell cycle progression and abrogate the cytokine-dependence of hematopoietic cells. Cell Cycle 3: 503-512, 2004.

54. Kawamata N, Chen J and Koeffler HP: Suberoylanilide hydroxamic acid (SAHA; vorinostat) suppresses translation of cyclin D1 in mantle cell lymphoma cells. Blood 110: 2667-2673, 2007.

55. Yu C, Rahmani M, Dent P and Grant S: The hierarchical relationship between MAPK signaling and ROS generation in human leukemia cells undergoing apoptosis in response to the proteasome inhibitor Bortezomib. Exp Cell Res 295: 555-566, 2004.

56. Yu C, Subler M, Rahmani M, et al: Induction of apoptosis in BCR/ABL+ cells by histone deacetylase inhibitors involves reciprocal effects on the RAF/MEK/ERK and JNK pathways. Cancer Biol Ther 2: 544-551, 2003.

57. Yagi Y, Fushida S, Harada S, et al: Effects of valproic acid on the cell cycle and apoptosis through acetylation of histone and tubulin in a scirrhous gastric cancer cell line. J Exp Clin Cancer Res 29: 149, 2010.

58. Gatti L, Benedetti V, De Cesare M, et al: Synergistic interaction between the novel histone deacetylase inhibitor ST2782 and the proteasome inhibitor bortezomib in platinum-sensitive and resistant ovarian carcinoma cells. J Inorg Biochem 113: 94-101, 2012.

59. Hwang JJ, Kim Ys, Kim T, et al: A novel histone deacetylase inhibitor, CG200745, potentiates anticancer effect of docetaxel in prostate cancer via decreasing Mcl-1 and Bcl-XL. Invest New Drugs 30: 1434-1442, 2012.

60. Fuino L, Bali P, Wittmann S, et al: Histone deacetylase inhibitor LAQ824 down-regulates Her-2 and sensitizes human breast cancer cells to trastuzumab, taxotere, gemcitabine, and epothilone B. Mol Cancer Ther 2: 971-984, 2003.

61. Huang Y and Waxman S: Enhanced growth inhibition and differentiation of fluorodeoxyuridine-treated human colon carcinoma cells by phenylbutyrate. Clin Cancer Res 4: 2503-2509, 1998.

62. Kim MS, Blake M, Baek JH, et al: Inhibition of histone deacetylase increases cytotoxicity to anticancer drugs targeting DNA. Cancer Res 63: 7291-7300, 2003.

63. Maggio SC, Rosato RR, Kramer LB, et al: The histone deacetylase inhibitor MS-275 interacts synergistically with fludarabine to induce apoptosis in human leukemia cells. Cancer Res 64: 2590-2600, 2004.

64. Witzig TE, Timm M, Stenson M, et al: Induction of apoptosis in malignant B cells by phenylbutyrate or phenylacetate in combination with chemotherapeutic agents. Clin Cancer Res 6: 681-692, 2000.

65. Linares A, Dalenc F, Balaguer P, et al: Manipulating protein acetylation in breast cancer: a promising approach in combination with hormonal therapies. J Biomed Biotechnol 2011: 856985, 2011

66. Munster PN, Thurn KT, Thomas S, et al: A phase II study of the histone deacetylase inhibitor vorinostat combined with tamoxifen for the treatment of patients with hormone therapyresistant breast cancer. Br J Cancer 104: 1828-1835, 2011.

67. Atmaca A, Al-Batran SE, Maurer A, et al: Valproic acid (VPA) in patients with refractory advanced cancer: a dose escalating phase I clinical trial. Br J Cancer 97: 177-182, 2007.

68. Duenas-Gonzalez A, Candelaria M, Perez-Plascencia C, et al: Valproic acid as epigenetic cancer drug: Preclinical, clinical and transcriptional effects on solid tumors. Cancer Treat Rev 34: 206-222, 2008.

69. Newland SE: The role of bioethics in international prescription drug market: economics and global justice. Penn Bioeth J 2: 8-12, 2006 . 